\title{
Oligodendroglia Are Particularly Vulnerable to Oxidative Damage after Neurotrauma In Vivo
}

\author{
Marcus K. Giacci, ${ }^{1}$ Carole A. Bartlett, ${ }^{1,4}$ Nicole M. Smith, ${ }^{1,2}$ K. Swaminathan Iyer, ${ }^{2}$ Lillian M. Toomey, ${ }^{4,5}$ \\ Haibo Jiang, ${ }^{3}$ Paul Guagliardo, ${ }^{3}{ }^{\circledR}$ Matt R. Kilburn, ${ }^{3}$ and ${ }^{\circledR}$ Melinda Fitzgerald ${ }^{1,4,5}$ \\ ${ }^{1}$ Experimental and Regenerative Neurosciences, School of Biological Sciences, ${ }^{2}$ School of Molecular Sciences, ${ }^{3}$ Centre for Microscopy, Characterisation, and \\ Analysis, University of Western Australia, Perth, 6009 Western Australia, Australia, ${ }^{4}$ Curtin Health Innovation Research Institute, Curtin University, \\ Bentley, Perth, 6102 Western Australia, Australia, and ${ }^{5}$ Perron Institute for Neurological and Translational Science, Sarich Neuroscience Research Institute, \\ Nedlands, 6009 Western Australia, Australia
}

Loss of function following injury to the CNS is worsened by secondary degeneration of neurons and glia surrounding the injury and is initiated by oxidative damage. However, it is not yet known which cellular populations and structures are most vulnerable to oxidative damage in vivo. Using Nanoscale secondary ion mass spectrometry (NanoSIMS), oxidative damage was semiquantified within cellular subpopulations and structures of optic nerve vulnerable to secondary degeneration, following a partial transection of the optic nerve in adult female PVG rats. Simultaneous assessment of cellular subpopulations and structures revealed oligodendroglia as the most vulnerable to DNA oxidation following injury. 5-Ethynyl-2'-deoxyuridine (EdU) was used to label cells that proliferated in the first $3 \mathrm{~d}$ after injury. Injury led to increases in DNA, protein, and lipid damage in oligodendrocyte progenitor cells and mature oligodendrocytes at $3 \mathrm{~d}$, regardless of proliferative state, associated with a decline in the numbers of oligodendrocyte progenitor cells at $7 \mathrm{~d} .04^{+}$preoligodendrocytes also exhibited increased lipid peroxidation. Interestingly, $\mathrm{EdU}^{+}$mature oligodendrocytes derived after injury demonstrated increased early susceptibility to DNA damage and lipid peroxidation. However, EdU ${ }^{-}$mature oligodendrocytes with high 8-hydroxyguanosine immunoreactivity were more likely to be caspase $3^{+}$. By day 28 , newly derived mature oligodendrocytes had significantly reduced myelin regulatory factor gene $\mathrm{mRNA}$, indicating that the myelination potential of these cells may be reduced. The proportion of caspase ${ }^{+}$oligodendrocytes remained higher in $\mathrm{EdU}^{-}$cells. Innovative use of NanoSIMS together with traditional immunohistochemistry and in situ hybridization have enabled the first demonstration of subpopulation specific oligodendroglial vulnerability to oxidative damage, due to secondary degeneration in vivo.

Key words: myelin regulatory factor gene; NanoSIMS; oligodendrocyte precursor cell; oligodendroglia; oxidative stress; proliferation and differentiation

Significance Statement

Injury to the CNS is characterized by oxidative damage in areas adjacent to the injury. However, the cellular subpopulations and structures most vulnerable to this damage remain to be elucidated. Here we use powerful NanoSIMS techniques to show increased oxidative damage in oligodendroglia and axons and to demonstrate that cells early in the oligodendroglial lineage are the most vulnerable to DNA oxidation. Further immunohistochemical and in situ hybridization investigation reveals that mature oligodendrocytes derived after injury are more vulnerable to oxidative damage than their counterparts existing at the time of injury and have reduced myelin regulatory factor gene mRNA, yet preexisting oligodendrocytes are more likely to die.

\section{Introduction}

Following injury to the CNS, secondary degeneration results in structural changes to axons and myelin, as well as death of neu- rons and glia in areas surrounding the initial injury site, leading to further loss of function (Lu et al., 2000; Park et al., 2004). However, it is not known which cellular populations and structures

Endowment Fund, and the State Government of Western Australian for contributing to the lon Probe Facility at the University of Western Australia.

The authors declare no competing financial interests.

Correspondence should be addressed to Dr. Melinda Fitzgerald, Sarich Neuroscience Research Institute, Curtin University, 8 Verdun St Nedlands 6009 WA Australia. E-mail: lindy.fitzgerald@curtin.edu.au.

DOI:10.1523/JNEUROSCI.1898-17.2018

Copyright $\odot 2018$ the authors $\quad 0270-6474 / 18 / 386491-14 \$ 15.00 / 0$ 
are most vulnerable to secondary degeneration in vivo. Secondary degeneration can be effectively modeled by a partial optic nerve transection, where dorsal axons are transected by the primary injury leaving initially unaffected ventral axons vulnerable to secondary degeneration (Fitzgerald et al., 2009a, 2010). As such, findings using the model are highly applicable to the development of therapeutic strategies to limit damage and functional loss following neurotrauma. Using this and other models, we and others have demonstrated that progression of secondary degeneration features oxidative stress, occurring as a consequence of the overproduction of reactive oxygen and nitrogen species, ultimately resulting in the oxidation of DNA, lipids, and proteins (Park et al., 2004; Xiong et al., 2007; O’Hare Doig et al., 2014). Reactive species and oxidative stress are observed early in the partial optic nerve transection model, with increased immunoreactivity of manganese superoxide dismutase in astrocytes as early as 5 min after injury in optic nerve vulnerable to secondary degeneration (Fitzgerald et al., 2010), and increased hypochlorous acid indicative of myeloperoxidase activity from macrophages in the injury site soon thereafter (O'Hare Doig et al., 2014). It has been postulated that selective vulnerability of oligodendroglia, particularly oligodendrocyte progenitor cells (OPCs) to oxidative damage (Back et al., 2002; Fünfschilling et al., 2012), may underlie much of the pathology of secondary degeneration (Szymanski et al., 2013). Previous studies have assessed oxidative damage to neurons (Coyle and Puttfarcken, 1993), glia and oligodendrocytes (Thorburne and Juurlink, 1996; Juurlink et al., 1998; Ziabreva et al., 2010). However, many of these studies have used immortalized cell lines or primary OPC cultures and compared relative expression of ion channels as a surrogate indicator of vulnerability. Comparative in vivo studies indicate that OPCs are more vulnerable than mature oligodendrocytes in neonatal hypoxic-ischemic injury (Back et al., 2002), whereas studies using inhibitors of complex IV indicate greater vulnerability of differentiated oligodendrocytes (Ziabreva et al., 2010). In vivo comparative measures of damage specific to neurons, myelin, OPCs, and oligodendrocytes following neurotrauma are lacking.

OPCs have an increased susceptibility to oxidative damage, attributed to their high iron content, low reduced glutathione levels (Thorburne and Juurlink, 1996), and low antioxidant defenses (French et al., 2009; Volpe, 2011). When considering neurotrauma, a loss in OPC numbers over time, with a concomitant increase in newly derived mature oligodendrocytes has been demonstrated following spinal cord injury (Watanabe et al., 2002). However, the influence of differentiation and proliferative state on cellular vulnerability following neurotrauma in vivo are yet to be explored. Selective vulnerability of OPCs is thought to impact upon function through both lack of availability of OPCs to generate new myelinating oligodendrocytes as well as compromised neuroglial signaling (Fields, 2015; Gautier et al., 2015). Importantly, the mechanisms driving depletion of OPCs are currently unknown, and it is not known whether proliferating cells are more susceptible to oxidative damage following neurotrauma.

Studies comparing the degree of damage in cellular subpopulations and structures, such as oligodendroglia, myelin, and paranodes, have not been possible using conventional immunohistochemical techniques, due to the inherent limitations of fluorescence microscopy. Using Nanoscale secondary ion mass spectrometry (NanoSIMS) to image metal isotope-conjugated antibodies, it is theoretically possible for simultaneous analysis of up to 100 antigens of interest, with the same level of reliability as immunohistochemistry (Angelo et al., 2014) and without secondary antibody emission overlap (Bandura et al., 2009). Nano-
SIMS images can be interpreted using immunointensity analysis techniques (Angelo et al., 2014; Lozić et al., 2016) that reveal comparative, semiquantitative information regarding the intensity of labeling in different cells and cellular components in the tissue. Here, oxidative damage to oligodendrocyte subpopulations and cell structures was compared in areas of white matter vulnerable to secondary degeneration following partial optic nerve transection, using NanoSIMS analysis. Complementary immunohistochemical and in situ hybridization analyses, identifying cells that had proliferated and/ or differentiated using 5-ethynyl-2-deoxyuridine (EdU), were used to illuminate functional significance of oxidative damage in specific oligodendroglial subpopulations, dependent upon DNA damage and proliferative status.

\section{Materials and Methods}

\section{Animal procedures}

All procedures involving animals were approved by the University of Western Australia Animal Ethics Committee (approval number RA3/ $100 / 673$ and RA3/100/1485) and adhered to the National Health and Medical Research Council Australian Code of Practice for the care and use of animals for scientific purposes. Adult female PVG rats were procured from the Animal Resources Centre (Murdoch, Western Australia) and housed under temperature-controlled conditions on a $12 \mathrm{~h}$ light/ dark cycle, with access to rat chow and water ad libitum. Female rats were used to complement our existing body of published work examining the pathology of secondary degeneration following partial optic nerve transection (Fitzgerald et al., 2009a; Payne et al., 2012; O'Hare Doig et al., 2014); the surgery for this valuable model is not practical in mice due to the size of the knife relative to the orbit and the presence of large blood vessels. The partial optic nerve transection procedure was conducted as described previously (Fitzgerald et al., 2010). In brief, rats were anesthetized with xylazine (10 mg/kg i.p. ilium Xylazil; Troy Laboratories), in combination with ketamine (50 $\mathrm{mg} / \mathrm{kg}$ Ketamil, Troy Laboratories), the dorsal aspect of the right optic nerve was incised to a depth of $200 \mu \mathrm{m}, 1$ $\mathrm{mm}$ behind the eye. Postoperative analgesia was provided once (2.8 $\mathrm{mg} / \mathrm{kg}$ s.c. carprofen, Norbrook). EdU (Invitrogen) was administered via intraperitoneal injection at $20 \mathrm{mg} / \mathrm{kg}$ to rats to be used for immunohistochemical outcomes twice a day at $12 \mathrm{~h}$ intervals for $3 \mathrm{~d}$, commencing during postoperative analgesia. All animals were killed with Lethabarb (sodium pentobarbitone $850 \mathrm{mg} / \mathrm{kg}$ plus sodium phenytoin $125 \mathrm{mg} / \mathrm{kg}$; Provet). Animals were transcardially perfused with saline followed by $4 \%$ PFA (Sigma-Aldrich) in 0.1 M phosphate buffer, $\mathrm{pH}$ 7.2-7.4. Optic nerves were harvested and postfixed in 4\% PFA (Sigma-Aldrich) for $1 \mathrm{~h}$ and then cryoprotected in $15 \%$ sucrose until cryosectioning. Optic nerves were cryosectioned transversely at $14 \mu \mathrm{m}$ thickness for immunohistochemistry and $10 \mu \mathrm{m}$ thickness for NanoSIMS.

\section{Experimental design and statistical analysis}

In total, 8 groups of animals were used for immunohistochemical and/or in situ hybridization outcomes; uninjured $3 \mathrm{~d}(n=10)$, injured $3 \mathrm{~d}(n=$ 10 for immunohistochemistry and $n=8$ for in situ hybridization and caspase 3 outcomes), uninjured $7 \mathrm{~d}(n=10)$, injured $7 \mathrm{~d}(n=10)$, uninjured $28 \mathrm{~d}(n=10)$, and injured $28 \mathrm{~d}(n=10$ for immunohistochemistry and $n=8$ for in situ hybridization and caspase 3 outcomes), with EdU administered to all animals. There were no significant differences recorded between the uninjured groups and therefore controls were combined for statistical comparisons. There were 2 groups used for NanoSIMS outcomes: uninjured $3 \mathrm{~d}(n=3)$ and injured $3 \mathrm{~d}(n=3)$. The numbers of animals per group for NanoSIMS analyses were appropriate given the fine-scale nature of the ultrastructural analysis and were similar to those described in published electron microscopy (Fitzgerald et al., 2009b; Xing et al., 2014) and NanoSIMS (Lozić et al., 2016) studies. Power analyses indicated that the numbers of animals per group would be sufficient to detect differences, based upon Type I/II errors of $\alpha=0.05$ and $\beta=0.2$ for both NanoSIMS and immunohistochemistry measures. The study design assessed between-subject factors, with no repeated 
Table 1. Antibodies and metal reagents used in immunolabelling for NanoSIMS assessments ${ }^{a}$

\begin{tabular}{|c|c|c|c|c|c|c|c|}
\hline Antigen & Vendor & Species & Catalog no. & Lot no. & Concentration $(\mu \mathrm{g} / \mathrm{ml})$ & Element & Reference \\
\hline $80 \mathrm{HdG}$ & Abcam & Goat & ab10802 & GR219814-6 & 1 & ${ }^{162}$ Dy & Haider et al., 2011 \\
\hline $\mathrm{CC} 1$ & Calbiochem & Mouse & ab16794 & D00140406 & 1 & ${ }^{158} \mathrm{Gd}$ & Guptarak et al., 2014 \\
\hline MBP & Abcam & Rabbit & ab40390 & GR250243-1 & 1 & ${ }^{175} \mathrm{Lu}$ & Fitzgerald et al., 2010 \\
\hline 3NT & Abcam & Rabbit & $06-284$ & 2506418 & 1 & ${ }^{170} \mathrm{Er}$ & Hartman et al., 2007 \\
\hline Caspr & Abcam & Rabbit & ab34151 & GR143918-2 & 1 & ${ }^{151} \mathrm{Eu}$ & Szymanski et al., 2013 \\
\hline$\beta \| I \mathrm{~T}$ & Sapphire Biosciences & Rabbit & ab18207 & GR204562-1 & 1 & ${ }^{176} \mathrm{Yb}$ & Eminli et al., 2008 \\
\hline NG2 & Abcam & Rabbit & ab83178 & 2387817 & 1 & ${ }^{172} \gamma b$ & Ye et al., 2016 \\
\hline Olig2 & R\&D Systems & Goat & af2418 & UPA0515011 & 1 & ${ }^{152} \mathrm{Sm}$ & Payne et al., 2013 \\
\hline
\end{tabular}

${ }^{a}$ The antigen, vendor, species, catalog number, lot number, and concentration used for labeling tissue and conjugated elements used.

measures, analyzing effects of injury, and time after injury, on a range of NanoSIMS and immunohistochemistry-based outcomes.

For NanoSIMS data sampling, $20 \times$ magnification light-microscopy images of H\&E-stained-optic nerve were used to select at least one FOV $(50 \mu \mathrm{m} \times 50 \mu \mathrm{m})$ in the ventral aspect of each optic nerve for NanoSIMS imaging. Additional FOV were used when available. Regions encompassing linear nuclei immediately ventral to the injury site, or equivalent in normal nerve, were selected for analysis. Choice of FOV was hypothesis driven; regions that would encompass a range of cell types and structural features in nerve exclusively vulnerable to secondary degeneration were actively selected. For immunohistochemistry and in situ hybridization sampling, a single FOV was selected per section, and there was one section per animal, located in ventral nerve at the injury site.

Data were expressed as mean \pm SEM. Statistical analyses were conducted using SPSS statistical software (IBM), comparing day 3, 7, and 28 injured tissue to grouped control groups using either one-way or twoway ANOVA with Bonferroni or Sidak post hoc tests as appropriate. Normality of data was assumed and homogeneity of variances was tested using Levene's test. $F, \mathrm{df}$, and $p$ values were presented for ANOVA tests; $p$ values alone were presented for post hoc comparisons. Student's paired $t$ tests were used for comparisons between in situ hybridization outcomes or proportions of caspase $3^{+}$cells, for 8 -hydroxyguanosine $(8 \mathrm{OHdG})$ low or high immunoreactivity subpopulations or for $\mathrm{EdU}^{-}$or $\mathrm{EdU}^{+}$ cells. For NanoSIMS analyses, variances were not homogeneous; therefore, a significance value of $p \leq 0.01$ was used. For immunohistochemistry and in situ hybridization analyses, where variances were equal, significance was set at $p \leq 0.05$. Significances less than $p=0.001$ are denoted as $p \leq 0.001$. Multiple comparisons were conducted in a hypothesis driven fashion, comparing the effects of injury and time after injury on the selected outcomes, in regions of the optic nerve established as vulnerable to secondary degeneration (Fitzgerald et al., 2009a).

\section{NanoSIMS}

Metal-antibody conjugation. Metal-conjugated primary antibodies were prepared using the MaxPAR antibody conjugation kit (DVS Sciences) according to the manufacturer's protocol (Table 1). Following the conjugation procedure, antibodies were diluted in PBS stabilization buffer: supplemented with $1 \%(\mathrm{w} / \mathrm{v})$ BSA (Thermo Fisher Scientific) and $0.05 \%$ (w/v) sodium azide (Sigma-Aldrich) at concentrations between 0.25 and $0.4 \mathrm{mg} / \mathrm{ml}$ and stored at $4^{\circ} \mathrm{C}$. Metal conjugation to the Click-iT EdU AlexaFluor-647 (Invitrogen) reagent was performed at a ratio of 4:1 ${ }^{144} \mathrm{Nd}$ :AlexaFluor-647, the ratio selected based on optimization using fluorescence spectrometry. Conjugation was demonstrated by spectral shift in the fluorescence emission. However, as excess unbound metal could not be sufficiently removed by extensive dialysis and interfered with sampling of other metals, the Click-iT reaction was not performed on this tissue.

Substrate preparation. TPO glass wafers (Corning) were precoated with $10 \mu \mathrm{g} / \mathrm{ml}$ poly-L-lysine (Sigma-Aldrich) for $1 \mathrm{~h}$ at room temperature, followed by $10 \mu \mathrm{g} / \mathrm{ml}$ laminin (Sigma-Aldrich) at $37^{\circ} \mathrm{C}$ overnight. Optic nerves were transversely cryosectioned at $10 \mu \mathrm{m}$ thickness. Sections to be used for NanoSIMS analysis were stained with H\&E free floating, then placed onto the precoated TPO glass wafer and allowed to adhere for $10 \mathrm{~min}$ at room temperature. The sections were then subjected to immunohistochemical procedures as previously described (Fitzgerald et al., 2010). In brief, sections were incubated for $24 \mathrm{~h}$ at $4^{\circ} \mathrm{C}$ with metal-conjugated primary antibodies recognizing 8OHdG (RRID:AB_297482), CC1 (RRID:AB_443473), myelin basic protein (MBP) (RRID:AB_1141521), 3-nitrotyrosine (3NT) (RRID:AB_310089), Caspr (RRID:AB_869934), $\beta$ III-tubulin ( $\beta$ IIIT) (RRID:AB_444319), NG2 (RRID:AB_10672215), and olig2 (RRID:AB_2157554), all at concentrations of $1 \mu \mathrm{g} / \mathrm{ml}$. Sections were then washed in PBS and left to dry before NanoSIMS imaging. Sections used as negative controls were incubated with buffer with no antibody or lanthanide metal at $4^{\circ} \mathrm{C}$ overnight.

NanoSIMS imaging. NanoSIMS analyses were performed with a CAMECA NanoSIMS 50L at the University of Western Australia. The sections were coated with gold to provide conductivity. Before each analysis, every FOV was presputtered with the primary beam to a dose of $>2 \times 10^{17}$ ions $/ \mathrm{cm}^{2}$. Elemental and isotopic maps were obtained using a Hyperion (H200) RF plasma oxygen ion $\left(\mathrm{O}^{-}\right)$source. The beam diameter was $\sim 100 \mathrm{~nm}$, the impact energy was $16 \mathrm{keV}$, and the beam current was $\sim 100 \mathrm{pA}$. Images were performed with a raster size of $50 \mu \mathrm{m}^{2}$, a resolution of $256 \times 256$ pixels, a dwell time of 9 ms per pixel and 12 planes were recorded for each FOV. The multicollection system was calibrated using metal isotope-conjugated antibodies, using antibody master mixes at a concentration of at least $1 \mathrm{~mm}$ lanthanide metal air dried on silicon wafers. Because sections were labeled with more than seven antibodies, each area was imaged twice with the following configurations: (1) ${ }^{41} \mathrm{~K}(\mathrm{H} \& \mathrm{E}),{ }^{144} \mathrm{Nd},{ }^{151} \mathrm{Eu}$ (Caspr), ${ }^{158} \mathrm{Gd}(\mathrm{CC} 1),{ }^{162} \mathrm{Dy}$ (8OHdG), ${ }^{170} \mathrm{Er}(3 \mathrm{NT})$, and ${ }^{175} \mathrm{Lu}(\mathrm{MBP})$; and $(2){ }^{27} \mathrm{Al}(\mathrm{H} \& \mathrm{E}),{ }^{144} \mathrm{Nd}$ (for preliminary EdU analysis), ${ }^{152} \mathrm{Sm}$ (olig2), ${ }^{158} \mathrm{Gd}(\mathrm{CC} 1),{ }^{162} \mathrm{Dy}$ (8OHdG), ${ }^{172} \mathrm{Yb}(\mathrm{NG} 2)$ and ${ }^{176} \mathrm{Yb}(\beta \mathrm{IIIT})$.

NanoSIMS quantification. NanoSIMS analyses result in secondary ion maps, with individual pixels representing the counts of secondary ions acquired within the acquisition time. The use of pseudo-coloring allows assignment of color to the lanthanide metal signals. White represents overlap of multiple colors, such as red, cyan, and purple. Analysis of these maps was conducted using the OpenMIMS plugin for Fiji (version 2.0; National Institutes of Health). Semiquantitative analyses of $8 \mathrm{OHdG}$ and $3 \mathrm{NT}$ (antibodies conjugated to ${ }^{162} \mathrm{Dy}$ and ${ }^{170} \mathrm{Er}$, respectively) were performed by determining the mean secondary ion count, defined as counts per pixel within specified ROI. The ROI were defined by manually tracing around areas with high secondary ion counts, present as a result of labeling with metal-conjugated antibodies recognizing $\beta$ IIIT, MBP, Caspr, NG2, olig2, or CC1 (antibodies conjugated to ${ }^{176} \mathrm{Yb},{ }^{175} \mathrm{Lu},{ }^{151} \mathrm{Eu}$, ${ }^{152} \mathrm{Sm}$, or ${ }^{158} \mathrm{Gd}$, respectively). Area and mean counts were reported as pixel intensity. Visualization of structural information was achieved using overlays of secondary ion images in Photoshop CC 2017 (Adobe), each assigned to a color channel as indicated on the respective images.

\section{Immunohistochemistry, microscopy, and analysis}

Immunohistochemical analyses were conducted according to previously described procedures (Fitzgerald et al., 2010). Primary antibodies used for immunohistochemical assessments were as follows: 8OHdG (1:400 or 1:1000, goat, Abcam, ab10802, RRID:AB_297482) (1:400, mouse, Abcam, ab62623, RRID:AB_940049), hydroxynonenal (HNE) (1:400, rabbit, Abcam, ab46545, RRID:AB_722490), 3NT (1:500, rabbit, Abcam, ab61392, RRID:AB_942087), NG2 (1:400, mouse, Abcam, ab50009, RRID:AB_881569), olig2 (1:500, goat, R\&D Systems, AF4218, RRID: AB_2157554), CC1 (1:500 or 1:750, mouse, Calbiochem, ab16794, RRID:AB_443473), O4 (1:50, mouse, EMD Millipore, MAB345, RRID: AB_94872), MBP (1:300, rabbit, Abcam, RRID:AB_1141521), and 
activated-caspase3 (1:500, rabbit, Abcam, ab13847, RRID:AB_443014). Secondary antibodies were species-specific AlexaFluor-350, -488 , and -555-conjugated antibodies (1:500; Invitrogen). $\mathrm{EdU}^{+}$cells were visualized using a Click-iT EdU AlexaFluor-647 Imaging Kit (Invitrogen) according to the manufacturer's instructions. Similarly, TUNEL ${ }^{+}$cells were visualized using a Click-iT TUNEL AlexaFluor-488 Imaging Kit (Invitrogen) according to the manufacturer's instructions.

In situ hybridization analyses were conducted using the RNAscope Multiplex Fluorescent Reagent Kit version 2 system, using custom-made probes to myelin regulatory factor gene (MYRF) and ID2 (both C1 hybridized), Sox10 and Nkx2.2 (both C2 hybridized); Nkx2.2 outcomes were somewhat variable and are not described further. The Multiplex Fluorescent Reagent Kit version 2 and TSA amplification (PerkinElmer) was used largely according to the manufacturer's instructions (document 323100-USM) with the following optimizations: pretreatment was with $5 \mathrm{~min}$ boiling in target retrieval reagent, followed by $20 \mathrm{~min} 33 \%$ protease incubation at room temperature. Immunohistochemistry was conducted after completion of the in situ hybridization protocol and was followed by EdU detection in accordance with recommendations in technical note $323100-\mathrm{TN}$, using primary antibody dilutions of 1:300 for CC1 (RRID:AB_443473), 1:250 for 8OHdG (RRID:

AB_297482) and 1:300 for MBP (RRID:AB_1141521), incubating overnight at room temperature. Secondary antibodies were donkey anti-goat AlexaFluor-350 (1:250; Invitrogen) for 8OHDG and CC1 and TSA amplification (PerkinElmer) with biotinylated secondary antibodies and streptavidin-HRP for NG2 (RRID:AB_10672215) and CC1 (RRID: AB_443473) as appropriate. TSA fluorescein and Cy3 and Cy5 fluorophores (PerkinElmer) were used to amplify each of the fluorescent signals for the three or four color analyses, in accordance with the instructions in the Multiplex Fluorescent Reagent Kit version 2.

Fluorescence imaging was performed using an Sil inverted microscope (Nikon). Images were captured in a stack of 13 visual slices at 0.5 $\mu \mathrm{m}$ increments along the $z$-axis, obtained from the middle $6 \mu \mathrm{m}$ of the optic nerve section. All images for assessment of each outcome measure were captured at a constant exposure, using identical microscope settings. The selected FOVs were located in ventral optic nerve directly below the dorsal primary injury site. A single FOV was selected per section, and there was one section per animal. Images were deconvolved using autoquant blind deconvolution with Nikon Elements AT software. OPCs were identified as $\mathrm{NG}_{2}{ }^{+} / \mathrm{olig} 2{ }^{+}$cells, premyelinating $\mathrm{O} 4$ cells were identified as $\mathrm{O}_{4}^{+}$and mature OLs were identified as $\mathrm{CC} 1^{+}$cells (Payne et al., 2013). O4 immunoreactivity was present diffusely on cell processes, so $\mathrm{O}^{+}{ }^{+}$cells were defined as cells with $>50 \% \mathrm{O} 4$ immunoreactivity surrounding a Hoechst ${ }^{+}$nucleus. $\mathrm{EdU}^{+}$cells were defined as newly derived cells. Numbers of cells within oligodendroglial subpopulations were quantified. This nonstereological technique does not allow for an estimate of total cell numbers within the nerve but does allow for comparative assessment between time points after injury. 8OHdG, 3NT, and HNE immunointensities were assessed within ROI defined by the oligodendroglial identification markers for OPCs, premyelinating oligodendrocytes, and mature oligodendrocytes on a single, central visual slice. Similarly, intensities of in situ hybridization signal were assessed within ROI defined by NG2 for OPCs and CC1 for mature oligodendrocytes, on a single, central visual slice. The presence of the analyzed transcription factors further confirmed cellular identity within the oligodendroglial lineage (Wang et al., 2001; Fancy et al., 2004; Liu et al., 2007; Emery et al., 2009). Subpopulations of cells were analyzed for
mRNA expression or the proportion of $\mathrm{TUNEL}^{+}$or caspase ${ }^{+}$cells, based upon whether $8 \mathrm{OHdG}$ immunoreactivity in these cells was above or below an arbitrarily defined and constant threshold, or whether they were $\mathrm{EdU}^{-}$or $\mathrm{EdU}^{+}$. The mean intensity of MBP immunoreactivity in an area immediately surrounding $\mathrm{CC}^{+}$oligodendrocytes was also quantified, separately for $\mathrm{EdU}^{-}$and $\mathrm{EdU}^{+}$cells. Analysis of immunointensity and cell numbers were performed using Fiji analysis software. Normalization to background is not possible for oxidative stress immunointensity data, as the oxidized proteins, lipid, and DNA are diffusely distributed throughout the tissue, and there is nowhere that can be conclusively described as background. Data shown are mean arbitrary fluorescence intensities for $8 \mathrm{OHdG}, 3 \mathrm{NT}$, HNE, and MBP as well as for ID2, Sox10, and MYRF mRNA. Mean counts of OPCs, O4s, and mature oligodendrocyte cells were expressed at number of cells $/ \mathrm{mm}^{2}$. Numbers of $\mathrm{TUNEL}^{+}$or caspase $3^{+}$cells were expressed as a proportion of the total number of $\mathrm{CC}^{+}$mature oligodendrocytes.

\section{Results}

The NanoSIMS was used to compare the vulnerability of cellular subpopulations and structures within regions of secondary degeneration following neurotrauma in vivo. Imaging of metal isotope-conjugated antibodies using NanoSIMS has been demonstrated to have the same level of reliability as immunohistochemistry (Angelo et al., 2014), without secondary antibody emission overlap (Bandura et al., 2009).

\section{Identification of oxidative damage in oligodendroglia, myelin structures, and axons}

To capitalize on the semiquantitative information inherent in the secondary ion images produced by NanoSIMS, regions of lanthanide metal/antibody labeling indicating cell subtypes or structural features were analyzed. FOV for analysis were selected using longitudinally oriented optic nerve sections viewed by light microscopy (Fig. 1a). The dark streaks (arrow) visualized via the 

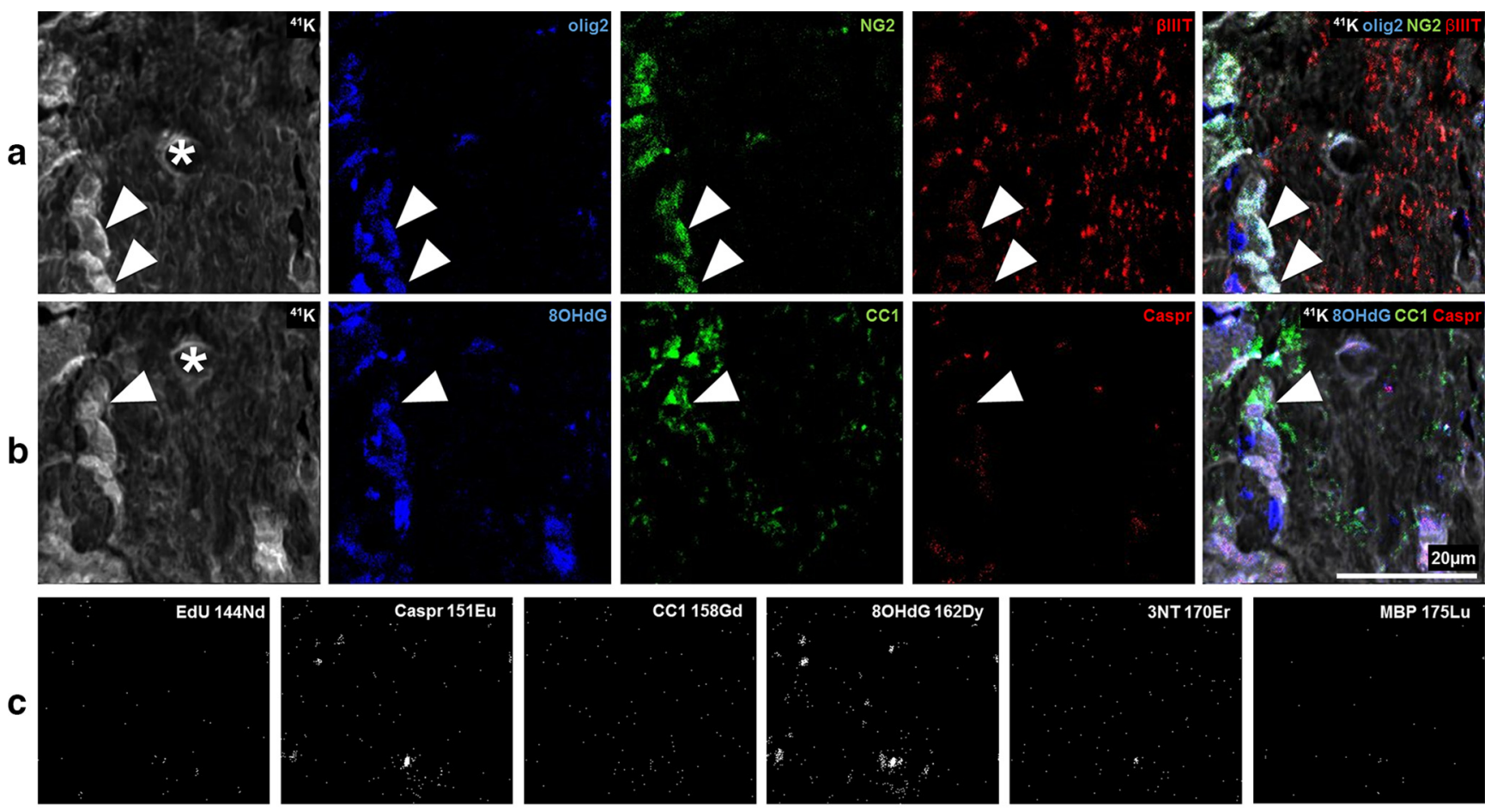

cc1 158Gd
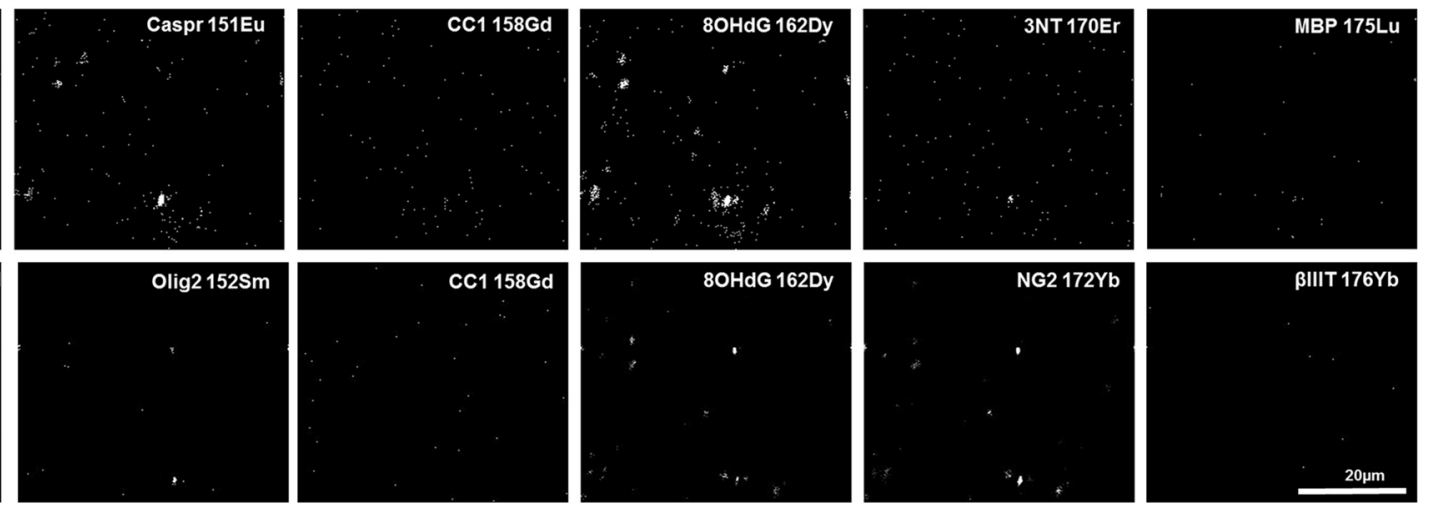

Figure 2. Pseudofluorescence composite images confirming appropriate pixel distribution of metal-labeled antibodies of interest and negative controls. The pseudofluorescent composite images show distinctly different pixel distributions. $\boldsymbol{a}, \boldsymbol{b}$, The same FOV from normal optic nerve, captured using the two NanoSIMS scan settings described in Figure 1, to detect specific lanthanide-metal-conjugated antibodies of interest. $a,{ }^{41} \mathrm{~K}$ (gray) shows the location of nucleic and cytoplasmic regions. 0 lig2 (blue) and NG2 (green) indicate 0PCs when colocalized (arrowheads). 0 lig 2 and $\beta$ IIIT (red) are present in nuclei and cytoplasm, respectively. $\boldsymbol{b}, 80 \mathrm{HdG}$ (blue) staining pattern colocalizes with nuclei (arrowhead), within CC ${ }^{+}$(green) mature oligodendrocytes. $(C 1$ and Caspr (red) labeling, both in the cytoplasm, with distinct staining patterns in line with their known cell structure distributions. *Center of the image from the first imaging scan. The NanoSIMS images of tissue not incubated with lanthanide-conjugated antibody. $\boldsymbol{c}, \boldsymbol{d}$, Distinctly different pixel distribution from the sections labeled with lanthanide-conjugated antibodies shown in Figure 1 (and $\boldsymbol{a}$, $\boldsymbol{b}) . \boldsymbol{c}, \boldsymbol{d}$, The same FOV from normal optic nerve, captured using the NanoSIMS scan settings described in Figure 1 to detect the specific lanthanide metals of interest. $\boldsymbol{c}$, Images acquired using the NanoSIMS calibrated to detect the following: ${ }^{144} \mathrm{Nd},{ }^{151} \mathrm{Eu},{ }^{158} \mathrm{Gd},{ }^{162} \mathrm{Dy},{ }^{170} \mathrm{Er}$, and ${ }^{175} \mathrm{Lu}$. $d$, The acquisition of ${ }^{144} \mathrm{Nd},{ }^{152} \mathrm{Sm},{ }^{158} \mathrm{Gd},{ }^{162} \mathrm{Dy},{ }^{172} \mathrm{Yb}$, and ${ }^{176} \mathrm{Yb}$ within the same FOV. The NanoSIMS scan setting used to detect specific metal lanthanides are indicated on each image $(\boldsymbol{c}, \boldsymbol{d})$.

H\&E staining are nuclei and likely represent oligodendroglia arranged in linear arrays, as described in studies of oligodendroglial development (Walsh et al., 2016). FOV were chosen to encompass these features. Intensities of metal/antibody labeling indicating oxidative damage within these defined regions were semiquantified, making it possible to compare oxidative damage between these cellular subpopulations and structures, for a specific indicator of oxidative damage. We did not attempt to compare intensity of labeling between oxidative damage indicators, as while the degree of metal labeling is consistent for any individual outcome measure, intensity may be different for different antibodies. ROIs were identified based on elevated pixel intensities of the metals bound to antibodies recognizing CC1 for mature but not necessarily myelinating oligodendrocyte somata, MBP for myelin ensheathing axons, Caspr for paranodes, $\beta$ IIIT for axons, and NG2 and olig2 for oligodendroglia (Fig. 1). The pixel intensity of $8 \mathrm{OHdG}$ and $3 \mathrm{NT}$ labeling in these ROI were then determined to semiquantify DNA oxidation and protein nitration, respectively. Two sets of comparisons were conducted: the first assessing the effects of injury on pixel intensities within each cellular subpopulation or structure, and the second compar- ing pixel intensities in the various subpopulations or structures to each other. The FOV captured by the NanoSIMS and used in these first analyses were too small to identify sufficient numbers of $\mathrm{NG} 2^{+} / \mathrm{olig} 2^{+}$cells for valid statistical analysis of oxidative damage within OPCs. Therefore $\mathrm{NG}_{2}{ }^{+}$and olig $2^{+}$ROI were analyzed separately. However, it is important to note that the olig2 ${ }^{+}$transcription factor is expressed in all oligodendroglia (Payne et al., 2013) and NG2 ${ }^{+}$profiles include pericytes (Ozerdem et al., 2002), as well as neuronal stem cells (Richardson et al., 2011), astrocytes (Zhu et al., 2008), and areas of extracellular matrix (Busch and Silver, 2007). The use of pseudo-coloring allowed assignment of color to the lanthanide metal signals, and overlay of these colors is as expected (e.g., blue overlaid with red appears purple). Tissue sections labeled with lanthanideconjugated antibodies displayed expected labeling patterns. For example, olig2 was present in nuclei identified on ${ }^{41} \mathrm{~K}$ images of the same FOV, and $\mathrm{NG}_{2}{ }^{+}$and $\mathrm{CC}_{1}{ }^{+}$ROI corresponded to expected cellular distributions (Fig. 2a,b, arrowheads). The NanoSIMSs images are generated as a reflection of ablation of a very small depth of tissue. As such, not all features expected in tradi- 

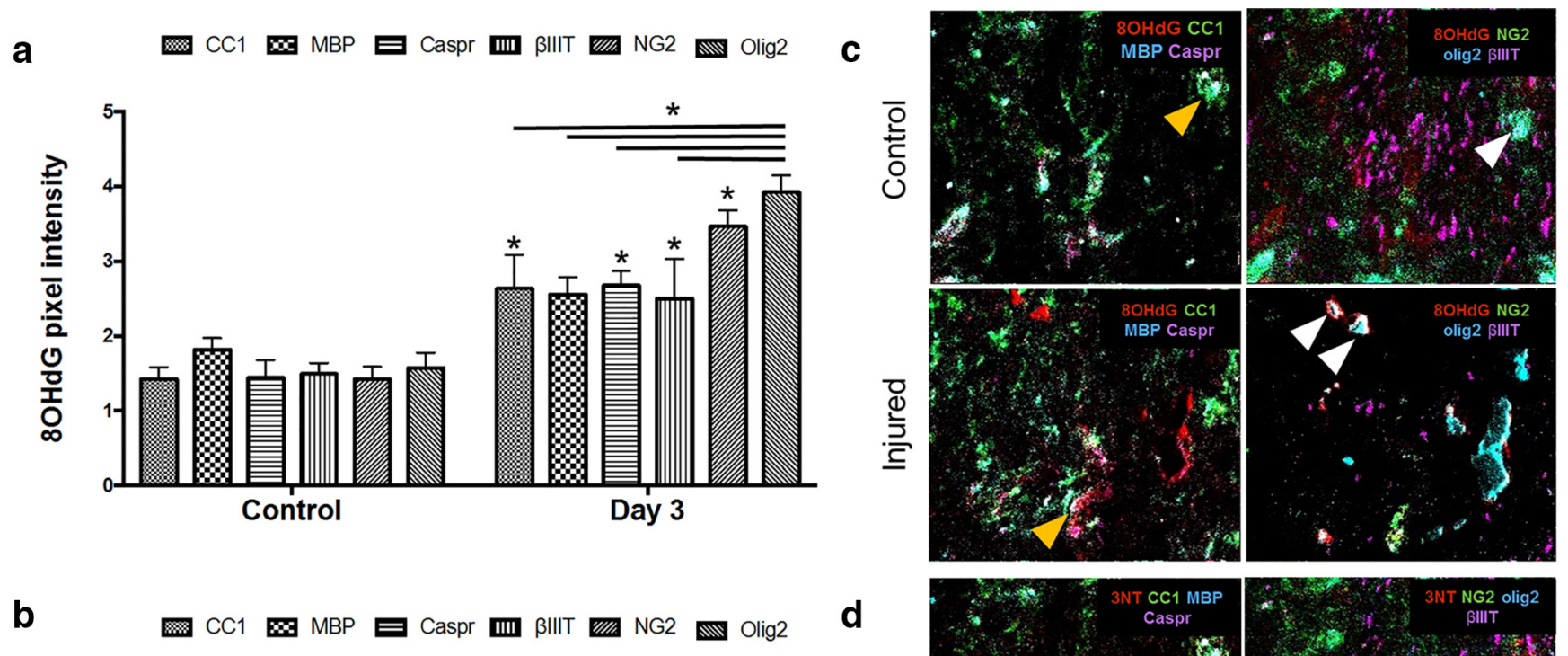

\section{d}
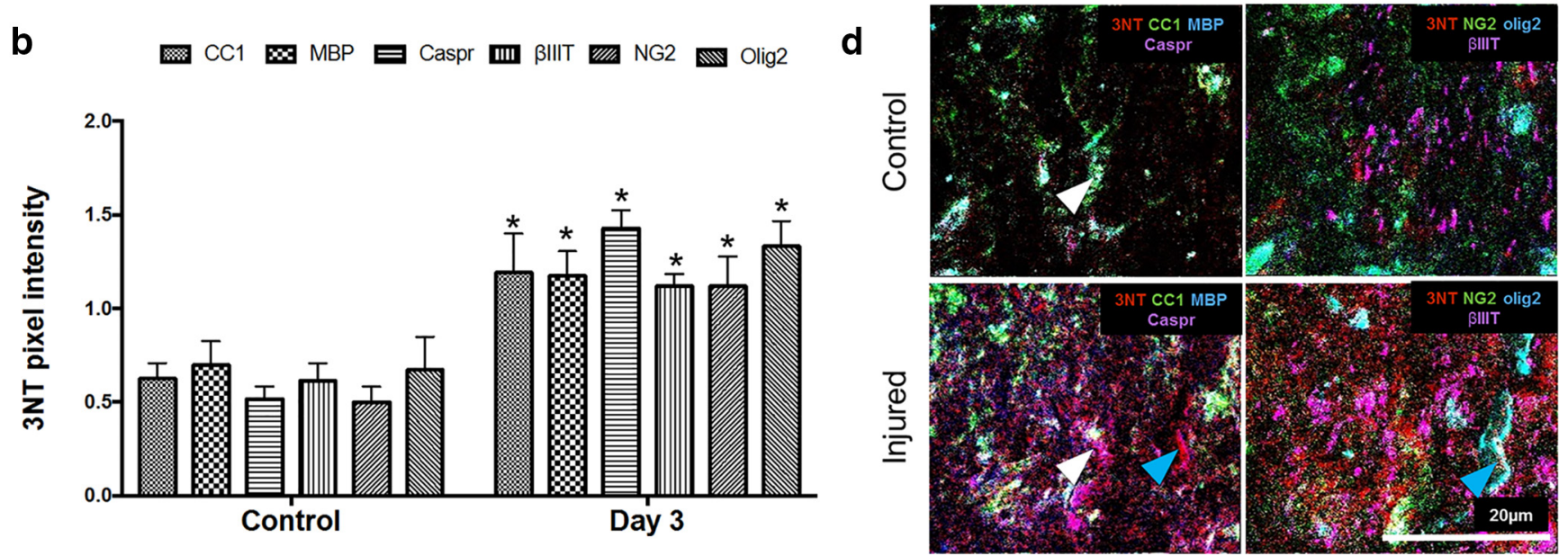

Figure 3. Comparative analysis of DNA oxidation and protein nitration in cellular subpopulations and structures vulnerable to secondary degeneration in vivo. $\boldsymbol{a}$, Mean \pm SEM pixel intensity indicating increased DNA oxidation in $\mathrm{CC}^{+}{ }^{+}, \mathrm{Caspr}^{+}, \mathrm{NG2}^{+}$, and olig2 ${ }^{+}$areas following injury relative to control $\left(^{*}\right)$, as well as significant increases in DNA oxidation in olig2 ${ }^{+}$areas compared with other cellular subpopulations and structures following injury ( ${ }^{*}$ over bar). $\boldsymbol{b}$, Mean \pm SEM pixel intensity indicating increased protein nitration in CC1 ${ }^{+}, \mathrm{MBP}^{+},{ }, \mathrm{Caspr}{ }^{+},{ } \beta \mathrm{IIIT}{ }^{+}, \mathrm{NG2}^{+}$, , and olig2 ${ }^{+}$areas following injury $\left(^{*}\right)$. Representative pseudofluorescent composite images show (c) DNA oxidation (red) in CC ${ }^{+}$(green), Caspr ${ }^{+}$(purple), NG2 ${ }^{+}$(green), and olig2 ${ }^{+}$(blue) areas in control and injured optic nerve and (d) protein nitration (red) within $\mathrm{CC}^{+}{ }^{+}$(green), $\mathrm{MBP}^{+}$(blue), Caspr ${ }^{+}$(purple), $\mathrm{NG}^{+}$(green), olig2 ${ }^{+}$(blue), and $\beta \mathrm{IIIT}{ }^{+}$(purple) areas. 80HdG and 3NT images for control and injured nerve were each taken of the same FOV. c, Orange arrowheads indicate $\mathrm{CC}^{+}{ }^{+}$(green) regions before and after injury. There is an increase in $80 \mathrm{HdG}$ (red) pixel intensity within these regions after injury. $\boldsymbol{c}$, White arrowheads indicate olig2 ${ }^{+}$areas. There is higher expression of $80 \mathrm{HdG}$ (red) colocalized within these areas compared with other areas. $\boldsymbol{d}$, White arrowheads indicate examples of $\mathrm{CC}^{+}{ }^{+}$(green) areas colocalizing with 3NT (red) regions more with injury. Blue arrowheads indicate 3 NT signal in the first image of injured tissue, colocalizing with white olig2/NG2/3NT in the second image. ${ }^{*} p \leq 0.01 . n=3 /$ group.

tional immunohistochemistry images will be apparent (e.g., Caspr representation) (Fig. 2a,b). Control tissue sections not incubated with lanthanide-conjugated antibody were largely blank (Fig. $2 c, d$ ).

8 OHdG pixel intensities within mature oligodendrocytes $(p=0.003), \mathrm{NG}^{+}{ }^{+}$areas $(p \leq 0.001)$, olig2 ${ }^{+}$cells $(p \leq 0.001)$, $\beta$ IIIT $^{+}$axons $(p=0.004)$, and paranodal areas $(p=0.001)$ were significantly increased $3 \mathrm{~d}$ after injury, compared with these cell populations and structures in uninjured tissue $(F=3.438, \mathrm{df}=$ 10, two-way ANOVA) (Fig. 3a,c), demonstrating increased DNA oxidation in all of these structures vulnerable to secondary degeneration. In contrast, $8 \mathrm{OHdG}$ pixel intensity colocalised with MBP did not change from control after injury $(p=0.046$; requirement for significance is $p \leq 0.01$ due to the lack of homogeneity of variances) (Fig. 3a). Olig2 ${ }^{+}$cells showed significantly higher levels of colocalized $8 \mathrm{OHdG}$ pixel intensity than mature $\mathrm{CC}^{+}$oligodendrocytes $(p \leq 0.001)$, MBP $(p \leq 0.001)$, Caspr $(p=0.001)$, or axons $(p \leq 0.001)$ at $3 \mathrm{~d}$ after injury (Fig. $3 a, c)$, indicating selective vulnerability of OPCs to DNA oxidation. To- gether, the data indicate selective vulnerability of oligodendroglial DNA to oxidative stress in regions remote from the initial injury site.

Assessments of 3NT pixel intensity revealed that protein nitration increased at $3 \mathrm{~d}$ after injury in mature oligodendrocytes $(p=0.002), \mathrm{NG}^{+}$cells $(p=0.002)$, olig ${ }^{+}$cells $(p \leq 0.001)$, $\beta$ IIIT $^{+}$axons $(p=0.004)$, and paranodes $(p \leq 0.001)(F=$ 0.752 , df $=10$, two-way ANOVA) (Fig. $3 b, d$ ). However, in contrast to the higher DNA oxidation observed in Olig ${ }^{+}$cells, comparisons between ROI in terms of $3 \mathrm{NT}$ pixel intensity at $3 \mathrm{~d}$ after injury showed no significant differences between the cell populations and structures (Fig. $3 b, d$ ). It is important to view the NanoSIMS images in the context of the multiple images of the same FOV. For example, some of the red 3NT signal in the first image of Figure $3 d$ (injured, blue arrow) appears not to be colocalized with a cellular element. However, if compared with the adjacent image of the same FOV, the red signal can be seen to colocalize with the white olig2/NG2/3NT signal. Comparisons in basal levels of DNA oxidation and protein nitration between 

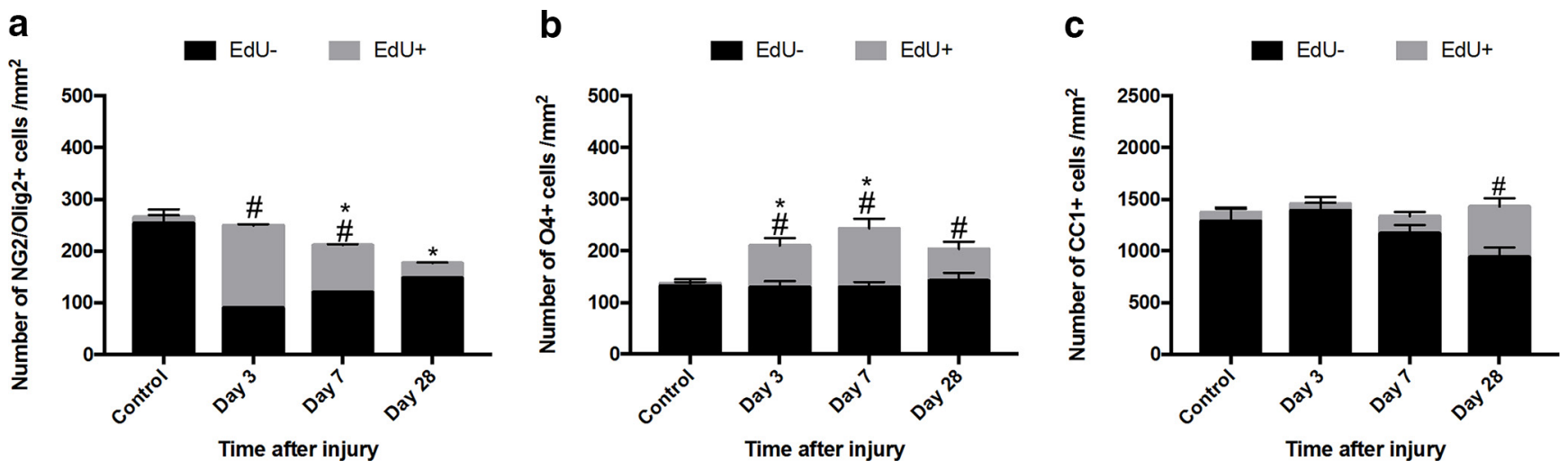

Figure 4. Proliferation of oligodendroglial subpopulations vulnerable to secondary degeneration in vivo. Oligodendroglia of varying maturity were identified with antibodies to NG2/olig2 (0PCs), 04 (premyelinating oligodendrocytes), and CC1 (mature oligodendrocytes). Proliferating subpopulations were distinguished by EdU ${ }^{+}$labeling and were observed at varying time points after injury in $(\boldsymbol{a})$ OPCs, (b) 04s, and (c) CC1 ${ }^{+}$cells. $\boldsymbol{a}-\boldsymbol{c}$, Quantification of the mean densities \pm SEM of OPCs, 04, and CC $1^{+}$cells, respectively. Black bars represent densities of EdU ${ }^{-}$cells. Gray bars represent densities of EdU ${ }^{+}$cells. ${ }^{\#} p \leq 0.05$, differences in the number of EdU ${ }^{+}$cell numbers from control. ${ }^{*} p \leq 0.05$, differences in the total density (sum of EdU ${ }^{-}$and EdU ${ }^{+}$subpopulations) compared with control.

oligodendroglia, axons, and myelin proteins in uninjured tissue did not reveal any significant differences between any of the markers (Fig. 3a,b).

Population dynamics of newly derived and previously existing oligodendroglia during secondary degeneration To gain a better understanding of oligodendroglial population dynamics, the proliferation and differentiation of these cells were assessed using traditional immunohistochemistry to detect subpopulations of oligodendroglia along the differentiation lineage; cells that had proliferated in the $3 \mathrm{~d}$ after injury were labeled with EdU in vivo. Following injury, there was a significant increase in the number of newly derived OPCs at days 3 ( $p \leq 0.001)$ and 7 $(p \leq 0.001)$ following injury compared with uninjured controls $(F=3.78, \mathrm{df}=117$, two-way ANOVA $)$. Despite the increase in the number and proportion of newly derived OPCs, the total numbers of OPCs (newly derived and previously existing populations together) decreased in areas of secondary degeneration $7 \mathrm{~d}$ after injury $(p=0.029)$, and remained depleted at $28 \mathrm{~d}$ ( $p \leq$ 0.001 ) (Fig. 4a). Dying cells were quantified using TUNEL staining; however, the numbers of these cells were low, precluding useful statistical comparisons (data not shown).

There was a significant increase in the numbers of newly derived $\mathrm{EdU}^{+}$premyelinating oligodendrocytes $\left(\mathrm{O} 4^{+}\right)$at $3(p \leq$ $0.001), 7(p \leq 0.001)$ and $28(p=0.004)$ days after injury $(F=$ 2.85 , df $=79$, two-way ANOVA) (Fig. $4 b)$. The total numbers of $\mathrm{O} 4{ }^{+}$cells increased at $3(p=0.037)$ and $7(p=0.001)$ days after injury compared with controls (Fig. $4 b$ ). It has been previously documented that, in the uninjured, mature CNS, there is a relatively slow turnover of mature OLs (Young et al., 2013). Similarly, we observed very low numbers of newly derived EdU ${ }^{+}$ mature OLs in control uninjured animals, and only in 2 animals. Following injury, there was a significant increase in the numbers of newly derived mature oligodendrocytes at $28 \mathrm{~d}$ following injury $(p \leq 0.001)(F=6.28, \mathrm{df}=119$, two-way ANOVA) (Fig. $4 c)$. It is worthwhile noting that, while these data are a snapshot in time and cannot be taken as cumulative, the total number of newly derived mature oligodendrocytes (Fig. 4c) was lower than the sum of the numbers of newly derived OPCs or of premyelinating oligodendrocytes at 3, 7, and $28 \mathrm{~d}$ (Fig. 4a,b).

Oxidative damage to oligodendroglia following neurotrauma It is widely acknowledged that oligodendroglia are vulnerable to oxidative stress (Roth and Núñez, 2016). However, direct com- parisons between oxidative damage in newly derived oligodendroglial subpopulations and subpopulations existing at the time of injury, within regions of secondary degeneration in vivo have not yet been conducted. Accordingly, the immunointensities of markers indicating oxidative damage to DNA, proteins, and lipids were compared in $\mathrm{EdU}^{+}$and $\mathrm{EdU}^{-} \mathrm{OPC}$, premyelinating, and mature oligodendrocyte subpopulations.

DNA oxidation was significantly increased in both newly derived $(p \leq 0.001)$ and previously existing $(p \leq 0.001)$ OPCs $3 \mathrm{~d}$ after injury, compared with control animals $(F=1.164, \mathrm{df}=92)$; newly derived and preexisting OPC DNA oxidation returned to control levels at 7 and $28 \mathrm{~d}$ after injury (Fig. $5 a$ ). Both populations of OPCs displayed increased protein nitration, indicated by $3 \mathrm{NT}$ immunointensity $3 \mathrm{~d}$ after injury (newly derived $p=0.002$, previously existing $p=0.050, F=2.306, \mathrm{df}=84$, two-way ANOVA); this also returned to control levels at 7 and $28 \mathrm{~d}$ after injury (Fig. $5 b)$. Similarly, both newly derived and preexisting OPCs showed increased immunofluorescence of HNE in OPCs at $3 \mathrm{~d}$ after injury $(p=0.017$ and $p \leq 0.001$, respectively, $F=1.780$, $\mathrm{df}=92$, two-way ANOVA), which returned to control levels at 7 and $28 \mathrm{~d}$ after injury (Fig. 5c). There were no differences between EdU ${ }^{+}$ and $\mathrm{EdU}^{-}$OPCs in terms of the degree of oxidative damage after injury, regardless of the oxidative damage indicator (Fig. $5 d-f$; $\mathrm{EdU}^{-}$cells indicated by $>, \mathrm{EdU}^{+}$cells indicated by $\gg$ ). The data indicate that OPCs have transient increases in oxidative damage to DNA, lipid, and protein at $3 \mathrm{~d}$ after injury.

Analysis of $\mathrm{O}^{+}{ }^{+}$cells showed no increases in $8 \mathrm{OHdG}(p>$ $0.05, F=0.406, \mathrm{df}=71$, two-way ANOVA) (Fig. $6 a)$ or $3 \mathrm{NT}(p>$ $0.05, F=0.391, \mathrm{df}=68$, two-way ANOVA) (Fig. $6 b$ ) immunoreactivity at any time point after injury, in either the newly derived or previously existing subpopulations. There was, however, a significant increase in HNE immunointensity in the nonproliferating $\mathrm{O}^{+}{ }^{+}$subpopulation at $3 \mathrm{~d}$ after injury $(p=0.001, F=$ 1.750, $\mathrm{df}=47$, two-way ANOVA) (Fig. $6 c$ ). The lack of newly derived $\mathrm{EdU}^{+} \mathrm{O} 4+$ cells in the control group rendered comparisons of $\mathrm{EdU}^{+}$cells derived after injury to control cells impossible; therefore, no statistical comparisons were made between newly derived $\mathrm{O} 4$ subpopulations (Fig. 6c). Representative images show $\mathrm{EdU}^{-}$cells indicated by $>, \mathrm{EdU}^{+}$cells indicated by $\gg$ (Fig. 6d-f).

Both newly derived $(p \leq 0.001)$ and preexisting $(p \leq 0.001)$ mature oligodendrocyte populations showed increased DNA oxidation $3 \mathrm{~d}$ after injury ( $F=1.189$, $\mathrm{df}=87$, two-way ANOVA), 


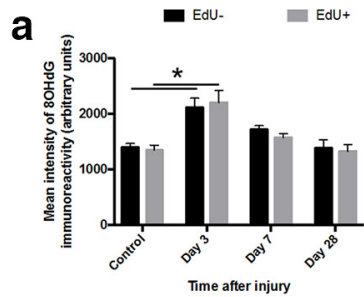

b

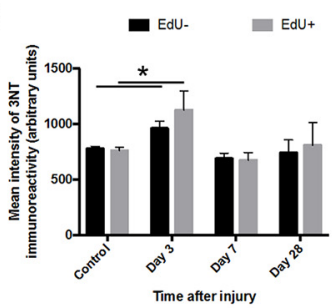

C

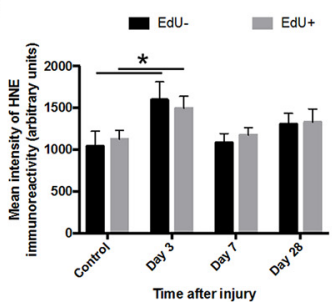

d

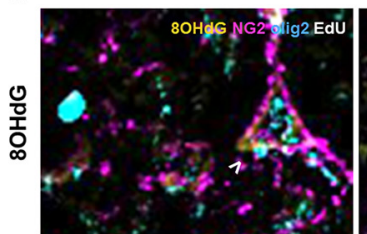

Control

e

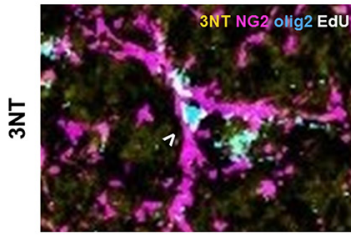

Control

$\mathbf{f}$

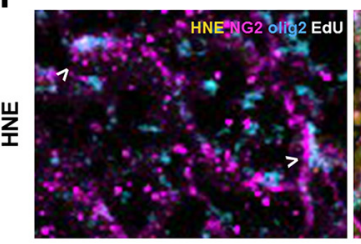

Control

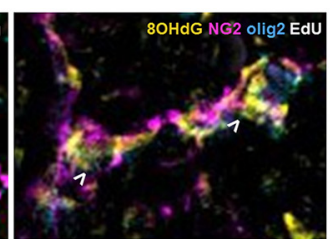

Day 3

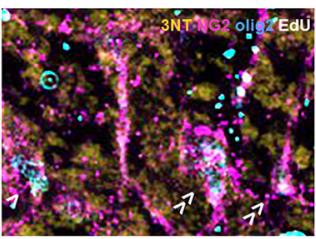

Day 3

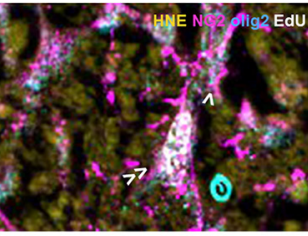

Day 3

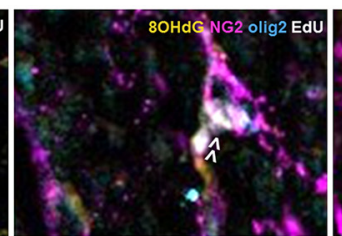

Day 7

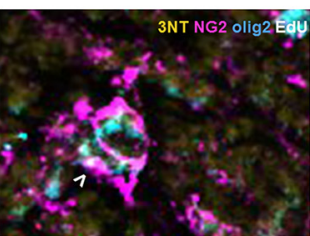

Day 7

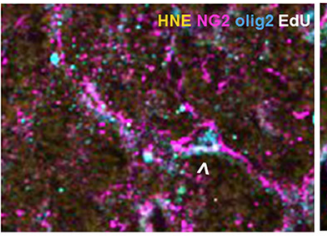

Day 7

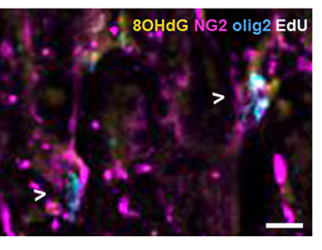

Day 28

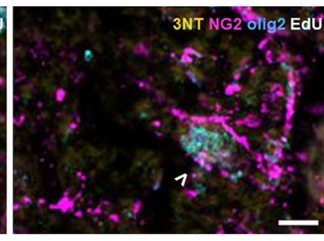

Day 28

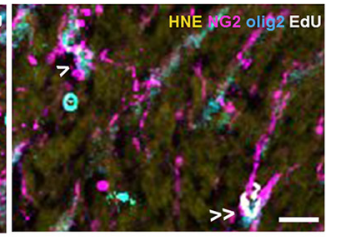

Day 28

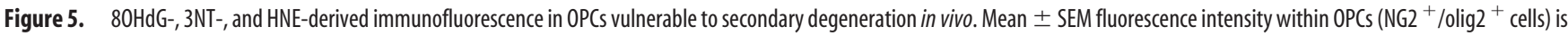
shown as follows: (a) $80 \mathrm{HdG}$, (b) 3NT, and (c): HNE labeling in uninjured optic nerve and at 3, 7, and $28 \mathrm{~d}$ following partial transection. Arbitrary values for immunofluorescence were categorized as EdU ${ }^{-}$(black bars) or EdU ${ }^{+}$(gray bars) to discriminate any differences due to proliferative state. Representative images of (d) $80 \mathrm{HdG}$, (e) 3NT, and (f) HNE labeling are of OPCs located within the ventral optic nerve vulnerable to secondary degeneration. $\boldsymbol{d}-\boldsymbol{f}$, Cells indicated are NG2 ${ }^{+} / 0 \mathrm{lig} 2^{+} / \mathrm{EdU}^{-}(>)$or NG2 ${ }^{+} / 0 \mathrm{olig}^{+} / \mathrm{EdU}^{+}(\gg)$. Statistical comparisons were made across and between groups. ${ }^{*} p \leq 0.05$, differences in immunointensity compared with controls. Scale bar: $\boldsymbol{d}-\boldsymbol{f}, 10 \mu \mathrm{m}$.

a

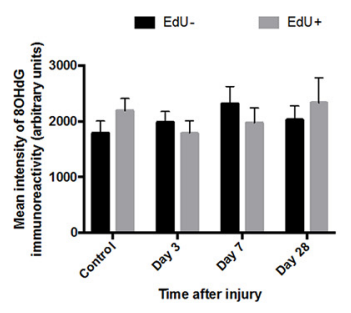

b

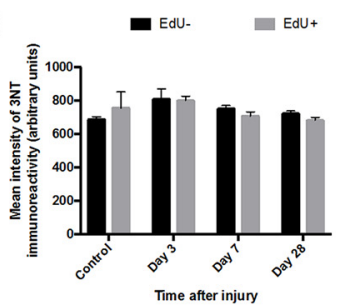

C

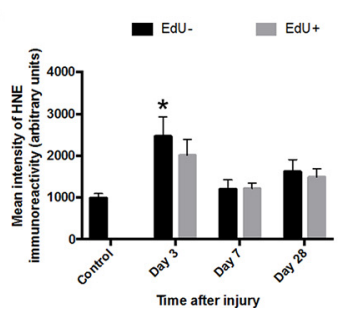

d

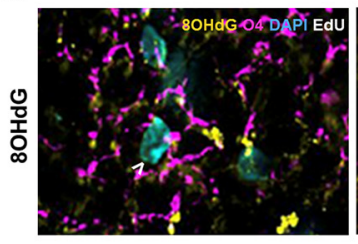

Control

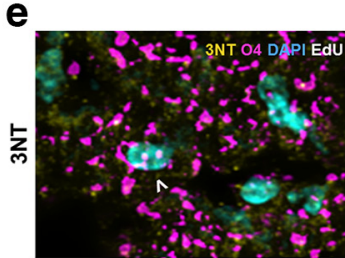

Control

f

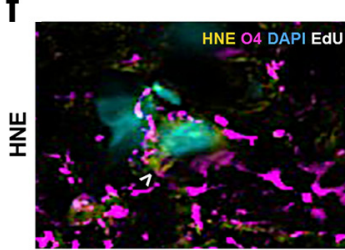

Control

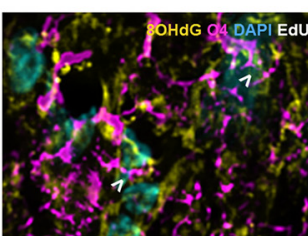

Day 3

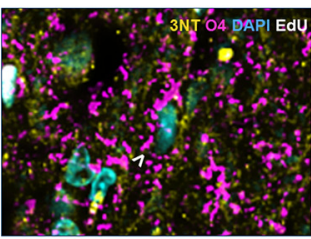

Day 3

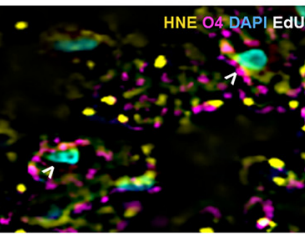

Day 3

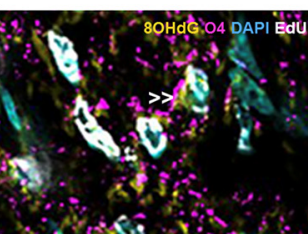

Day 7

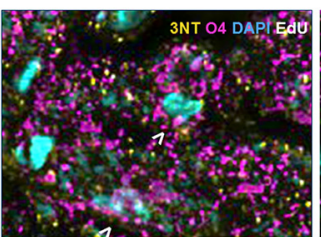

Day 7

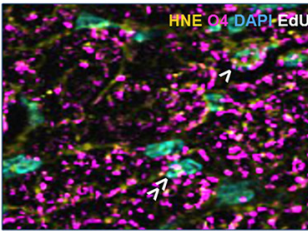

Day 7

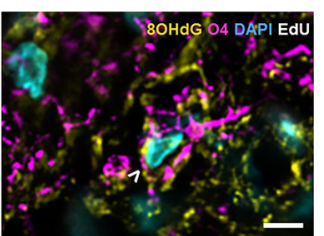

Day 28

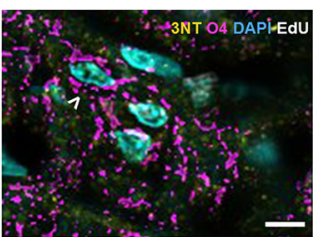

Day 28

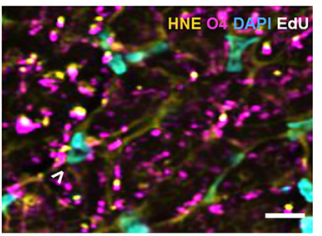

Day 28

Figure 6. $80 \mathrm{HdG}-3 \mathrm{NT}-$, and HNE-derived fluorescence in premyelinating oligodendrocytes vulnerable to secondary degeneration in vivo. Mean \pm SEM fluorescence intensity within premyelinating oligodendrocytes $\left(04^{+}\right.$cells) is shown as follows: $(\boldsymbol{a}) 80 \mathrm{HdG},(\boldsymbol{b}) 3 \mathrm{NT}$, and (c) HNE labeling in uninjured optic nerve and at 3, 7, and $28 \mathrm{~d}$ following partial transection. Arbitrary values for immunofluorescence were categorized as EdU ${ }^{-}$(black bars) or EdU ${ }^{+}$(gray bars) to discriminate any differences due to proliferative state. Representative images of (d) $80 \mathrm{HdG},(\boldsymbol{e}) 3 \mathrm{NT}$, and $(\boldsymbol{f}) \mathrm{HNE}$ labeling are of premyelinating oligodendrocytes located within the ventral optic nerve vulnerable to secondary degeneration. $d-f$, Cells indicated are $04^{+} / E \mathrm{EdU}^{-}(>)$or $04^{+} / \mathrm{EdU}^{+}(\gg)$. Statistical comparisons were made across and between groups. ${ }^{*} p \leq 0.05$, differences in immunointensity compared with controls. Scale bar: $\boldsymbol{d}-\boldsymbol{f}, 10 \mu \mathrm{m}$. 

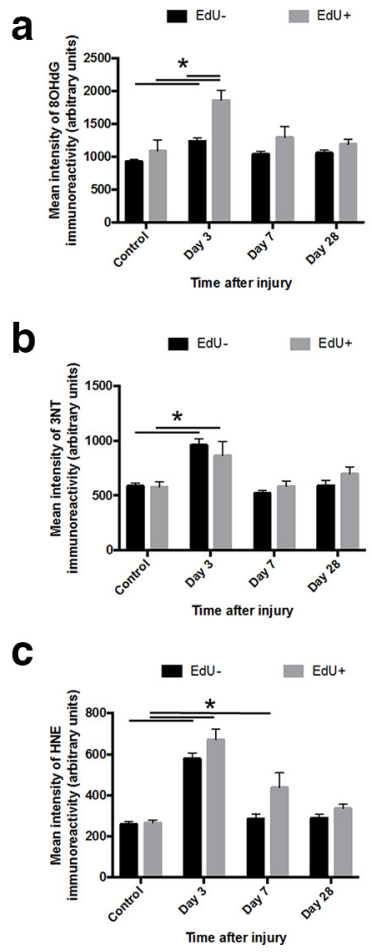

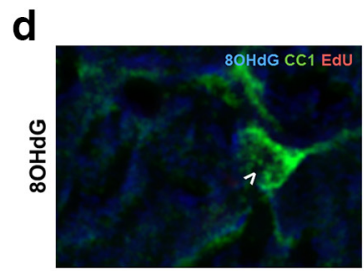

Control

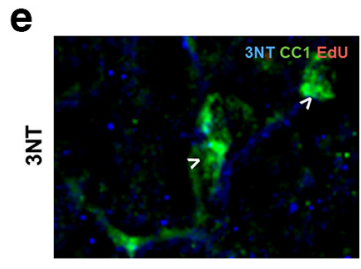

Control

f

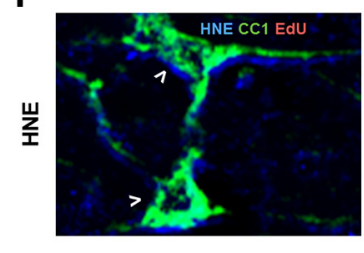

Control

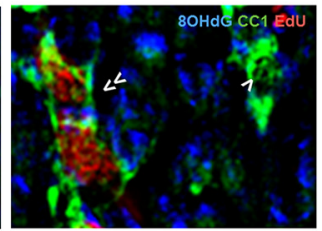

Day 3

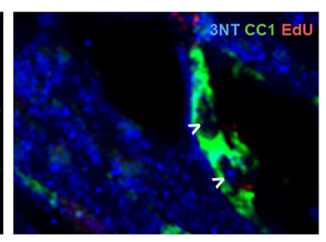

Day 3

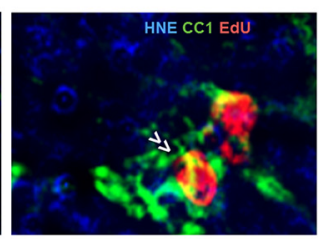

Day 3

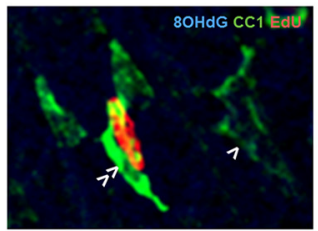

Day 7

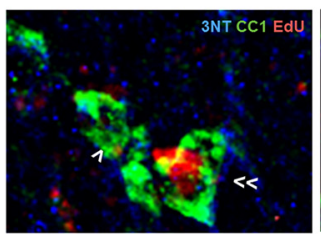

Day 7

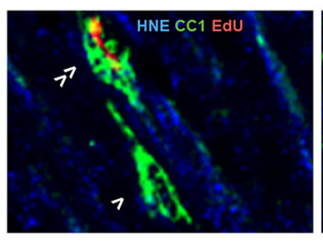

Day 7

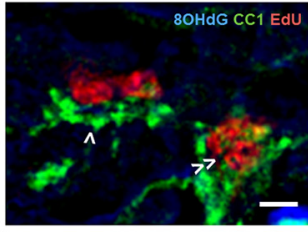

Day 28

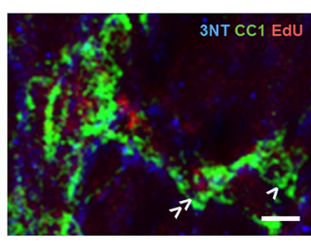

Day 28

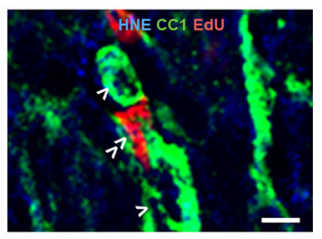

Day 28

Figure 7. $80 \mathrm{HdG}-3 \mathrm{NT}$-, and HNE-derived fluorescence in mature oligodendrocytes vulnerable to secondary degeneration in vivo. Mean \pm SEM fluorescence intensity within mature oligodendrocytes $\left(\mathrm{CC}^{+}\right.$cells) is shown following $80 \mathrm{HdG}(\boldsymbol{a}), 3 \mathrm{NT}(\boldsymbol{b})$, and $\mathrm{HNE}$ (c) labeling in uninjured optic nerve and at 3, 7, and $28 \mathrm{dfollowing} \mathrm{partial} \mathrm{transection.} \mathrm{Arbitrary} \mathrm{values} \mathrm{for} \mathrm{immunofluorescence}$ were categorized as $\mathrm{EdU}^{-}$(black bars) or EdU ${ }^{+}$(gray bars) to discriminate oligodendrocytes present at the time of injury and oligodendrocytes derived after injury. Representative images of $80 \mathrm{HdG}$ $(\boldsymbol{d})$, 3NT $(\boldsymbol{e})$, and HNE $(\boldsymbol{f})$ labeling are of mature oligodendrocytes located within the ventral optic nerve vulnerable to secondary degeneration. $\boldsymbol{d}-\boldsymbol{f}$, (ells indicated are $\mathrm{CC} 1^{+} / \mathrm{EdU} \mathrm{U}^{-}(>)$or $\left(\mathrm{C} 1^{+} / \mathrm{EdU}^{+}(\gg)\right.$. Statistical comparisons were made across and between groups. ${ }^{*} p \leq 0.05$, differences in immunointensity compared with controls. Scale bar, $\boldsymbol{d}-\boldsymbol{f}, 10 \mu \mathrm{m}$.

returning to control levels at 7 and $28 \mathrm{~d}$ (Fig. $7 a)$. Interestingly, newly derived $\mathrm{EdU}^{+}$mature oligodendrocytes displayed significantly higher DNA oxidation than their previously existing counterparts $3 \mathrm{~d}$ after injury ( $p \leq 0.001$ ), although, as shown in Figure $4 c$, this represents a very small proportion of the total numbers of mature oligodendrocytes (Fig. $7 a$; $\mathrm{EdU}^{-}$cells indicated by $>, \mathrm{EdU}^{+}$cells indicated by $\left.\gg\right)$. Similarly, both newly derived ( $p=0.001)$ and previously existing $(p \leq 0.001)$ populations of mature oligodendrocytes displayed increased protein nitration immunoreactivity $3 \mathrm{~d}$ after injury $(F=2.044, \mathrm{df}=90$, two-way ANOVA), returning to control levels at 7 and $28 \mathrm{~d}$ after injury. There were no statistically significant differences in 3NT immunoreactivity between previously existing and newly derived mature oligodendrocytes at any time point (Fig. $7 b$ ). Both EdU ${ }^{+}$ $(p \leq 0.001)$ and $\mathrm{EdU}^{-}(p \leq 0.001)$ mature oligodendrocytes demonstrated increases in lipid peroxidation $3 \mathrm{~d}$ after injury $(F=$ $4.08, \mathrm{df}=89$, two-way ANOVA). Newly derived mature oligodendrocytes maintained higher immunointensity of lipid peroxidation at $7 \mathrm{~d}$ after injury compared with their previously existing counterparts ( $p=0.003$ ), and relative to the immunointensity of control HNE $(p=0.010)$. Previously existing mature oligodendrocytes returned to control levels at this time. Representative images show $\mathrm{EdU}^{-}$cells indicated by $>, \mathrm{EdU}^{+}$cells indicated by $\gg$ (Fig. $7 d-f$ ).

Functional significance of oxidative damage to oligodendroglia following neurotrauma relative to proliferative state

The effects of increased oxidative damage to DNA on expression of mRNA for transcription factors associated with OPC differentiation and oligodendrocyte myelination were assessed using fluorescent in situ hybridization together with fluorescence immunohistochemistry. Comparisons were made between cells that were at baseline or had elevated $8 \mathrm{OHdG}$ immunoreactivity at $3 \mathrm{~d}$, as this was the time point at which most significant increases in $8 \mathrm{OHdG}$ were observed (Figs. 5-7). At day 28, populations were distinguished based upon whether they were $\mathrm{EdU}^{+}$and therefore newly derived soon after the injury; or $\mathrm{EdU}^{-}$, and were therefore either derived later than $3 \mathrm{~d}$ after injury, or were preexisting at the time of injury.

OPC differentiation factors ID2 (Wang et al., 2001; Havrda et al., 2014) and Sox 10 and MYRF (Stolt et al., 2002; Liu et al., 2007) were compared in $\mathrm{NG}_{2}{ }^{+}$or $\mathrm{CC}^{+}{ }^{+}$cells that were high or low in $8 \mathrm{OHdG}$ immunoreactivity, relying upon oligodendroglial transcription factors to confirm OPC identification. There were no changes in intensity of ID2 (Fig. $8 a ; p=0.65, \mathrm{df}=7, t$ test) or Sox10 expression (data not shown; $p=0.17, \mathrm{df}=7, t$ test) relative to $8 \mathrm{OHdG}$ immunoreactivity at day 3 , and there were also no differences relative to EdU defined proliferation status at day 28 (Fig. $8 b, \mathrm{ID} 2 ; p=0.09, \mathrm{df}=6, t$ test), although Levene's test indicated significantly greater variability in $\mathrm{EdU}^{+} \mathrm{OPCs}$ than in $\mathrm{EdU}^{-} \mathrm{OPCs}(p=0.03)$. Similarly, at day 3 after injury, increased 8 OHdG immunoreactivity did not lead to altered Sox10 ( $p=$ $0.17, \mathrm{df}=7, t$ test $)$ or MYRF ( $p=0.90, \mathrm{df}=7, t$ test) mRNA expression in $\mathrm{CCl}^{+}$mature oligodendrocytes (Fig. 8c,e). However, at day 28, while there was still no change in Sox 10 mRNA $(p=0.28, \mathrm{df}=6, t$ test $)$, newly derived $\mathrm{CC}^{+}$oligodendrocytes had significantly less MYRF mRNA ( $p=0.00, \mathrm{df}=6, t$ test $)$ than their preexisting counterparts (Fig. $8 d, f$; for representative image, see Fig. $8 g$ ). MYRF is a transcription factor, turned on as OPCs differentiate into oligodendrocytes, and critical for oligodendrocyte maturation (Koenning et al., 2012). Throughout life, MYRF 
a

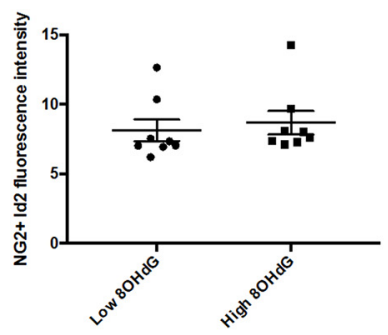

b

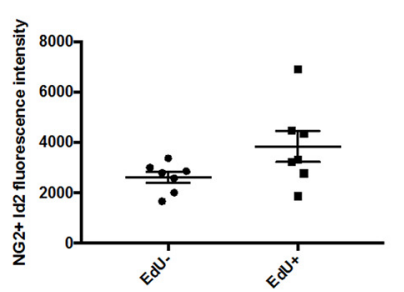

C

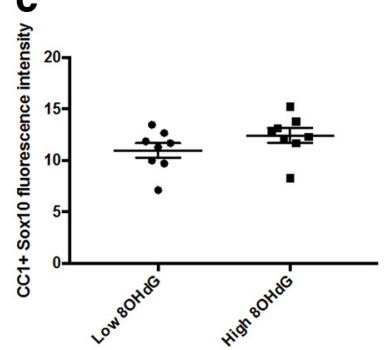

d

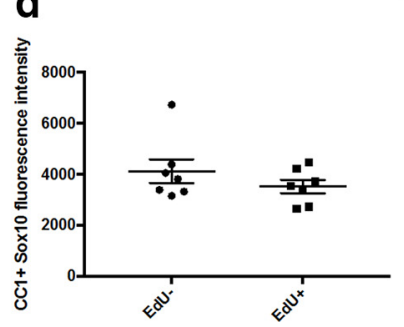

e

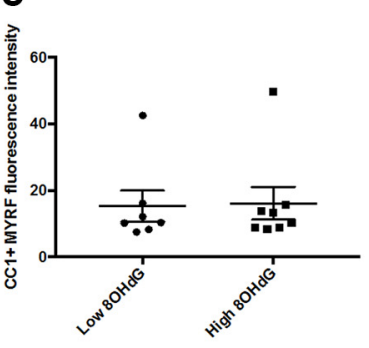

f

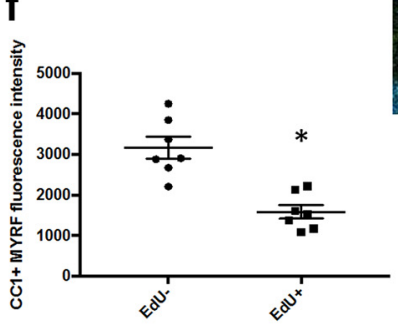

g DAPI CC1 MYRF EdU

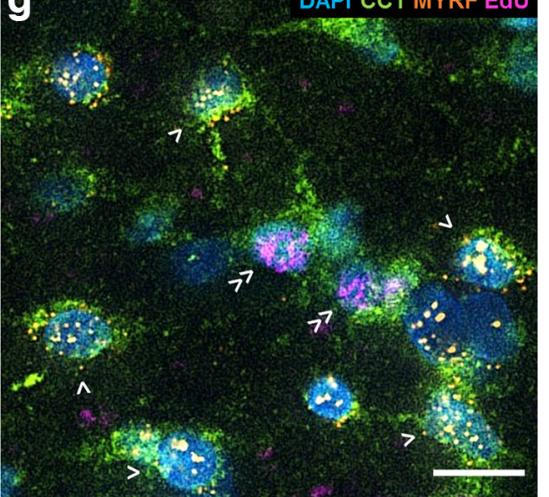

Figure 8. ID2, Sox10, and MYRF mRNA expression relative to 80HdG immunoreactivity or EdU defined proliferation status in 0PCs and oligodendrocytes. Fluorescence intensity of ID2 ( $\boldsymbol{a}, \boldsymbol{b})$, Sox10 $(\boldsymbol{c}, \boldsymbol{d})$, or MYRF $(\boldsymbol{e}, \boldsymbol{f})$ mRNA fluorescence in situ hybridization signal in NG2 ${ }^{+} \mathrm{OPCs}$ at $3(\boldsymbol{a})$ or $28(\boldsymbol{b})$ days after injury and in $\mathrm{CC}{ }^{+}{ }^{+}$mature oligodendrocytes at $3(\boldsymbol{c}, \boldsymbol{e})$ or $28(\boldsymbol{d}, \boldsymbol{f})$ days after injury. At $3 \mathrm{~d}$, comparisons are made between cells that have baseline or elevated $80 \mathrm{HdG}$ immunoreactivity; at $28 \mathrm{~d}$, comparisons are made between cells that are EdU ${ }^{-}$or EdU ${ }^{+}$. Each symbol represents the average for an animal. Error bars indicate mean values for the group. Statistical comparisons were made between groups. ${ }^{*} p \leq 0.05$, differences in fluorescence intensity. $\boldsymbol{g}$, Representative image at 28 d shows MYRF, EdU, CC1, and nuclei. CC1 ${ }^{+} / \mathrm{MYRF}^{+} / \mathrm{EdU}^{-}(>)$and $\mathrm{CC1}{ }^{+} / \mathrm{MYRF}^{-} / \mathrm{EdU}^{+}(\gg)$ cells are indicated; $\mathrm{MYRF}^{+} / \mathrm{EdU}^{+}$oligodendrocytes are seldom observed. Scale bar, $10 \mu \mathrm{m}$.

is also critical for oligodendrocyte myelin maintenance, and the loss of this factor can directly lead to significant demyelination (Koenning et al., 2012). As such, reduced MYRF may be indicative of reduced myelination capacity in newly derived oligodendrocytes. The immunoreactivity of MBP in the areas immediately surrounding $\mathrm{CC}^{+}{ }^{+}$oligodendrocyte somata was also quantified relative to proliferative status, at day 28 . MBP immunoreactivity immediately surrounding $\mathrm{EdU}^{+}$newly derived oligodendrocytes was not significantly less than that surrounding preexisting oligodendrocytes ( $p=0.33, \mathrm{df}=6, t$ test; data not shown). This is perhaps not surprising, given that myelin internodes are frequently $>100 \mu \mathrm{m}$ in length, depending upon the proliferative history of the cell, and the myelin measured close to a particular oligodendrocyte in a 2D plane may be formed by a different oligodendrocyte with its soma $40 \mu \mathrm{m}$ distant in any direction (Young et al., 2013).

The proportion of $\mathrm{CC}^{+}{ }^{+}$mature oligodendrocytes that were TUNEL $^{+}$and caspase $3^{+}$was compared for cells that were high or low in $8 \mathrm{OHdG}$ immunoreactivity at day 3. Mature oligodendrocytes with low $8 \mathrm{OHdG}$ immunoreactivity were generally not either $\mathrm{TUNEL}^{+}$or caspase $3^{+}$, and there was a significantly increased proportion of TUNEL ${ }^{+}$oligodendrocytes in the elevated 8 OHdG subpopulation (Fig. $9 a ; p=0.04$, df $=7, t$ test). Similar findings were observed when caspase 3 was used as an indicator of apoptotic cell death (Fig. $9 c ; p=0.00, \mathrm{df}=7, t$ test). For oligodendrocytes with elevated $8 \mathrm{OHdG}$, the proportion of $\mathrm{TUNEL}^{+}$cells was not different for EdU ${ }^{-}$and EdU ${ }^{+}$cells (Fig. $9 b ; p=0.53, \mathrm{df}=7, t$ test). However, when apoptotic death was considered more specifically (Degterev and Yuan, 2008), the percentage of caspase $3^{+}$cells was higher for $\mathrm{EdU}^{-}$than for EdU ${ }^{+}$ cells (Fig. $9 d ; p=0.00$, df $=7, t$ test). Similarly, at day 28 , the proportion of caspase $3^{+}$cells was significantly higher in $\mathrm{EdU}^{-}$ than $\mathrm{EdU}^{+}$mature oligodendrocytes (Fig. $9 e, f ; p=0.00, \mathrm{df}=7$, $t$ test).

\section{Discussion}

Multiplex NanoSIMS immunohistochemistry has enabled demonstration of selective vulnerability of oligodendroglia to DNA oxidation following neurotrauma in vivo. Detailed in vivo subpopulation and fate mapping analyses of oligodendroglial subpopulations along the differentiation lineage revealed susceptibility of OPCs and mature oligodendrocytes to DNA oxidation, protein nitration, and lipid peroxidation, with mature oligodendrocytes newly derived directly after injury more vulnerable than preexisting or later derived cells to DNA and protein damage. Reduced MYRF mRNA in the newly derived mature oligodendrocytes indicates that these cells may be compromised in their ability to make myelin. However, it is the $\mathrm{EdU}^{-}$cells that were preexisting at the time of injury that are more likely to die at day 3. $\mathrm{EdU}^{-}$oligodendrocyte vulnerability to death at day 28 may also include cells derived later after injury, and further studies will be required to assess effects of proliferation along a substantially more extended time course to differentiate vulnerability of later derived oligodendrocytes from their preexisting counterparts. The findings complement and extend previous studies suggesting vulnerability of oligodendroglia in vitro (Back et al., 1998; Fern and Möller, 2000) and in a range of pathologies, such as periventricular white matter damage (Back et al., 2005), hypoxia-ischemia and spinal cord injury (Watanabe et al., 2002) in vivo. Here we demonstrate higher levels of DNA oxidation in OPCs than axons and that OPC numbers decrease by $7 \mathrm{~d}$ after injury. We have previously demonstrated that retinal ganglion cells vulnerable to secondary degeneration do not begin to die until 2-3 weeks after injury (Fitzgerald et al., 2009a, b). Together, with the oxidative damage in mature oligodendrocytes at $3 \mathrm{~d}$, it is clear that changes to OPCs and oligodendrocytes precede loss of neurons in secondary degeneration and are likely to be a contributing factor to functional loss.

Using NanoSIMS, the cellular subpopulations and structures most vulnerable to oxidative damage within the CNS following 
a

b
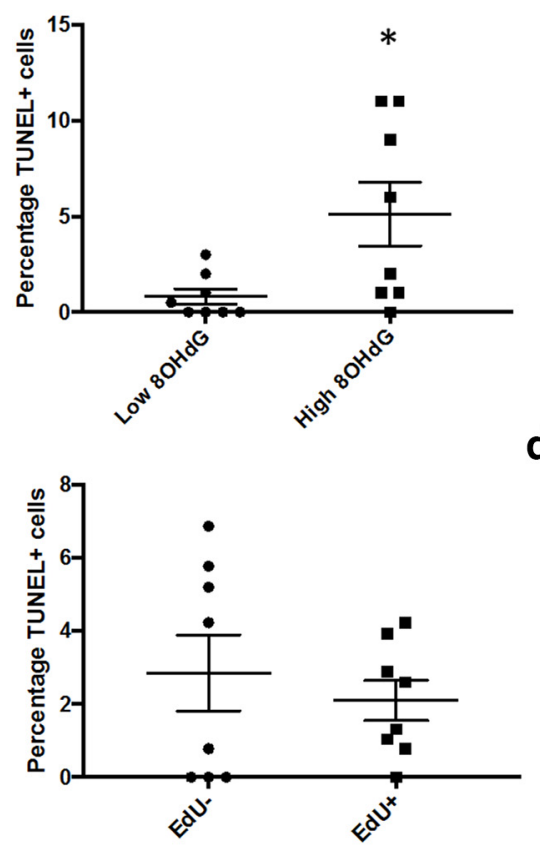

C

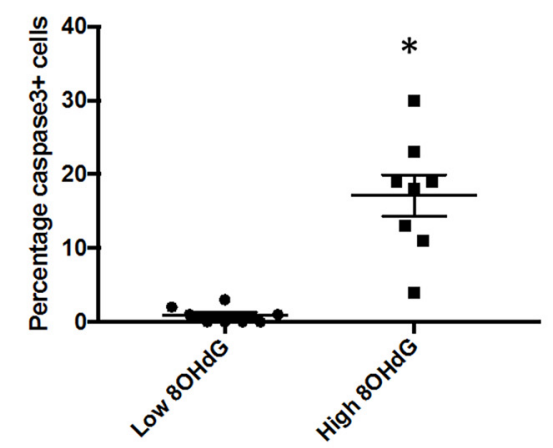

d

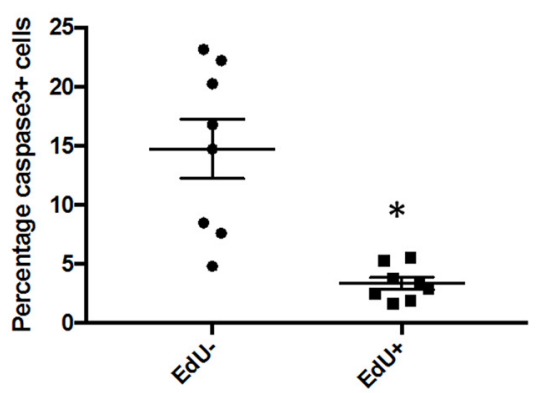

e
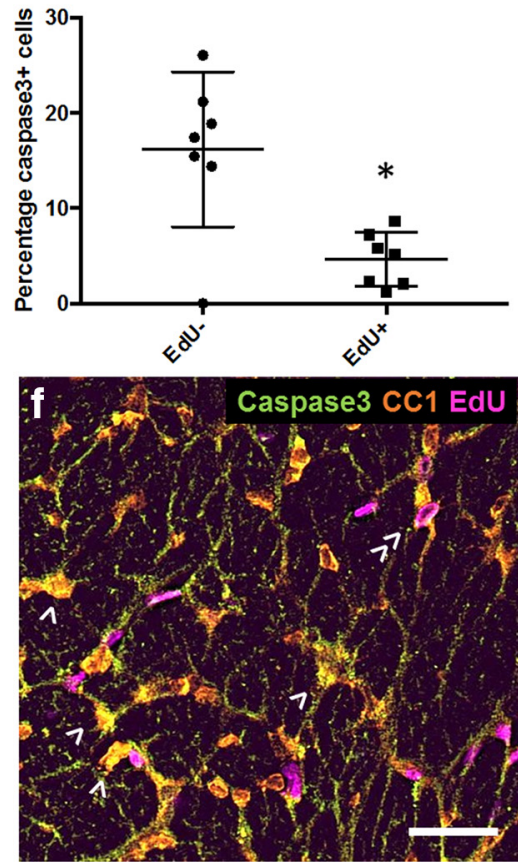

Figure 9. TUNEL labeling and caspase3 immunoreactivity relative to $80 \mathrm{HdG}$ immunoreactivity or EdU defined proliferation status in oligodendrocytes. Percentages of $\mathrm{CC} 1^{+}$oligodendrocytes that are TUNEL ${ }^{+}$at $3 \mathrm{~d}$ after injury; comparisons are made between all $\mathrm{CC}^{+}$cells based on $80 \mathrm{HdG}$ immunoreactivity $(\boldsymbol{a})$, then between EdU ${ }^{-}$and EdU ${ }^{+}$cells, both with elevated $80 \mathrm{HdG}(\boldsymbol{b})$. Similarly, percentages of $\mathrm{CC}^{+}$oligodendrocytes that are caspase $3^{+}$at $3 \mathrm{~d}$ after injury based upon $80 \mathrm{HdG}$ immunoreactivity $(\mathbf{c})$, then between EdU ${ }^{-}$and EdU ${ }^{+}$cells, both with elevated $80 \mathrm{HdG}$ (d).e, At $28 \mathrm{~d}$, caspase ${ }^{+}$oligodendrocyte comparisons are confined to $\mathrm{EdU}^{-/+}$as $80 \mathrm{HdG}$ immunoreactivity is not elevated. Each symbol represents the average for an animal. Error bars indicate mean values for the group. Statistical comparisons were made between groups. ${ }^{*} p \leq 0.05$, differences in percentages of TUNEL ${ }^{+}$or caspase ${ }^{+}$cells. $f$, Representative image of caspase3, EdU, $C(C 1$, caspase3, EdU and $\mathrm{CC} 1$ immunoreactivity at $28 \mathrm{~d} . \mathrm{CC}^{+} / \mathrm{caspase}^{+} / \mathrm{EdU}{ }^{-}(>)$and $\mathrm{CC}^{+} /$caspase $^{-} / \mathrm{EdU}^{+}(\gg)$ cells are indicated; caspase ${ }^{+} /$EdU ${ }^{+}$oligodendrocytes are seldom observed. Scale bar, $20 \mu \mathrm{m}$.

neurotrauma were identified. NanoSIMS imaging eliminates many of the limitations of multiplex imaging, as there are no autofluorescent background signals. Importantly, because the NanoSIMS has the capacity to resolve a fraction of a Dalton, there is no spectral overlap between mass-adjacent lanthanide metals. The quantitative accuracy between immunohistochemistry fluorescence intensity and NanoSIMS pixel intensity has been extensively tested, and linear regression analysis has revealed robust similarities between the two imaging methods (Angelo et al., 2014). NanoSIMS revealed DNA oxidation increased in oligodendroglial cell bodies following injury, whereas there were no such increases in myelin. $8 \mathrm{OHdG}$ is mainly expressed in the nuclei of cells but has also been identified within cytoplasmic regions via incorporation in mitochondrial DNA (Richter et al., 1988; Patel, 2002). The significant increase in DNA oxidation in $\mathrm{Caspr}^{+}$and $\beta \mathrm{IIIT}^{+}$regions may reflect oxidation of mitochondrial DNA, as mitochondria are freely able to enter and move throughout the axon and myelin sheath, with the highest number of mitochondria in the cytoplasmic ridges (Rinholm et al., 2016). It is worth noting that the mitochondria within the paranodal segment of the myelin sheath have a low surface area of cristae, indicative of low ATP production (Rinholm et al., 2016). Low ATP production in conjunction with a high proton-motive force and reduced coenzyme Q pool results in significantly higher production of reactive oxygen species (Murphy, 2009), which likely explains the increased DNA oxidation in $\mathrm{Caspr}^{+}$and not $\mathrm{MBP}^{+}$ regions. Olig2 ${ }^{+}$cells displayed significantly more DNA oxidation than the other cells and cellular structures measured, except $\mathrm{NG}_{2}{ }^{+}$cells, $3 \mathrm{~d}$ after injury. Olig2 is a transcription factor expressed throughout the oligodendroglial lineage (Wegner, 2001). Greater DNA oxidation in olig2 ${ }^{+}$cells than $\mathrm{CC}^{+}$mature oligo- dendrocytes, and an absence of statistically significant difference between olig2 ${ }^{+}$and $\mathrm{NG}_{2}{ }^{+}$regions indicates that OPCs exhibit more oxidative damage to DNA than the other tested cell types and cellular structures. DNA oxidation has been associated with severity of injury in a range of disease states (Nomoto et al., 2008; Tsai et al., 2011). Our findings, of a substantially greater proportion of both TUNEL ${ }^{+}$and caspase $3{ }^{+}$oligodendrocytes in the cell subpopulation that exhibit DNA damage, provide further evidence that oxidative damage to DNA will compromise affected cells. However, the situation is complex, as more of the $\mathrm{EdU}^{-}$ subpopulation of cells are dying by apoptotic mechanisms; oligodendrocytes derived soon after the injury appear to be protected from apoptotic cell death. Limitations with detection of EdU using NanoSIMS precluded assessment of caspase 3 in $\mathrm{NG}^{+}$/ olig ${ }^{+}$OPCs that were high in $8 \mathrm{OHdG}$. Nevertheless, together, our data indicate that oligodendroglia, and in particular perhaps OPCs, are the most vulnerable of the tested cellular populations and structures exposed to secondary degeneration in vivo.

OPCs that are $\mathrm{EdU}^{+}$have proliferated but not yet differentiated into later-stage oligodendroglia (Richardson et al., 2011). Our observed increase in the number of $\mathrm{O} 4 \mathrm{EdU}^{+}$cells occurred within a similar time frame after injury as OPC proliferation, implying that some OPC differentiation to $\mathrm{O} 4$ cells is occurring, but not precluding proliferation of $\mathrm{O} 4$ cells themselves. While these values are snapshots in time and do not represent cumulative numbers of $\mathrm{EdU}^{+} \mathrm{O} 4$ cells, the data indicate that there is differentiation from OPCs into $\mathrm{O} 4$ cells, particularly between days 3 and 7. Differentiated and/or newly derived O4 cells remain at the later $28 \mathrm{~d}$ time point, together with depletion of OPCs. We have demonstrated increased TUNEL ${ }^{+}$OPCs at 7 and $28 \mathrm{~d}$ after 
injury in this model, indicating that differentiation does not account for all of the OPC depletion (Payne et al., 2013).

$\mathrm{CC}^{+}$mature oligodendrocytes display increased DNA oxidation $3 \mathrm{~d}$ after injury, with a small subpopulation of newly derived oligodendrocytes exhibiting even higher DNA oxidation than their previously existing counterparts. There was no discernable decrease in the numbers of these mature preexisting cells until $28 \mathrm{~d}$ after injury. It has been demonstrated that senescent fibroblasts exhibit significantly higher levels of DNA oxidation than young cells (Chen et al., 1995), with foci of DNA damage particularly evident in newly senescent (i.e., recently divided cells) and associated with shortening of telomeres (von Zglinicki, 2002). Newly differentiated oligodendrocytes are susceptible to oxidative challenge (Ziabreva et al., 2010); however, differentiation does not necessary lead to increased oxidative damage to DNA (Covacci et al., 2001). We see that not all oligodendrocytes with elevated $8 \mathrm{OHdG}$ die, and newly derived oligodendrocytes with elevated $8 \mathrm{OHdG}$ have a lower percentage caspase $3^{+}$. Susceptibility of an individual cell likely depends on the interplay of multiple factors, including its proliferative history, antioxidant defenses, and the microenvironment to which it is exposed. Fate mapping data indicate that the newly derived mature oligodendrocytes are also vulnerable to lipid peroxidation but, nevertheless, go on to replace existing oligodendrocytes. However, these newly differentiated oligodendrocytes may not be able to generate myelin due to their substantially reduced levels of MYRF (Emery et al., 2009; Koenning et al., 2012; Bujalka et al., 2013; Hornig et al., 2013). Although it is not clear how much MYRF is required for myelination, these newly derived cells appear to be compromised and are likely to have reduced ability to generate new myelin to repair the damage of secondary degeneration. While we were unable to demonstrate reduced MBP adjacent to newly derived oligodendrocytes, the lack of a marker that identifies myelin associated with a particular oligodendrocyte soma in this rat model precludes definitive conclusions regarding whether myelin is produced by these cells. Nevertheless, the dysfunction of newly derived and increased early death of existing and also potentially later generated oligodendrocytes observed in the current study likely contributes to the dysmyelination and chronic loss of function observed during secondary degeneration at $28 \mathrm{~d}$ and 3 and 6 months in this model (Payne et al., 2012; Szymanski et al., 2013). OPC differentiation into mature myelinating oligodendrocytes ensheathing axons is a metabolically demanding process that increases the susceptibility of these myelinating oligodendrocytes to apoptosis (Garbern, 2007; Butts et al., 2008). This, in conjunction with the hostile environment present following neurotrauma, potentially culminates in the increased susceptibility to oxidative damage of myelinating oligodendroglia to death. Although some remyelination is indicated by the shorter internodes and increased number of intraperiodic lines observed at 3 months in this model (Payne et al., 2012, 2013), functional deficits persist, emphasizing the lack of effective myelin protection and/or repair.

It has generally been accepted that mature oligodendrocytes are postmitotic and are incapable of proliferating in response to injury (Mori and Leblond, 1970). Early reports of proliferation of oligodendrocytes in demyelinating lesions (Herndon et al., 1977) and following trauma (Ludwin, 1979) did not clearly differentiate between label incorporated into precursor cells that had newly differentiated, or that was incorporated directly into oligodendrocyte DNA, perhaps as a result of DNA repair. It is likely that the small number of $\mathrm{EdU}^{+}$mature oligodendrocytes seen in controls and at 3 and $7 \mathrm{~d}$ after injury in the current study were labeled as a result of DNA repair involving baseline levels of differentiation of OPCs. The larger increase in the numbers of newly derived oligodendrocytes at $28 \mathrm{~d}$ after injury are likely derived from maturing OPC populations, differentiating as a consequence of injury. It has been suggested that OPC differentiation into mature oligodendrocytes is compromised in models of multiple sclerosis (Mi et al., 2009; Fancy et al., 2010). However, the scenario following physical CNS injury may be different, as indicated in spinal cord injury (Zai and Wrathall, 2005) and by the significant numbers of newly differentiated oligodendrocytes observed in the current study. It is important to note that the current study assessed proliferation occurring immediately after injury; and although out of the scope of this study, it would be interesting to assess oxidative damage and differentiation in cellular subpopulations that arise within the multiple later phases of injury.

In conclusion, this work provides in vivo empirical evidence for the important role of oxidative damage in oligodendroglia in the pathology of secondary degeneration following neurotrauma. The semiquantification of oxidative damage to DNA, proteins, and lipids in oligodendroglia shows, for the first time, acute damage to specific subpopulations of these cells at different stages following injury. Future fate mapping of proliferating OPCs and their progeny beyond $28 \mathrm{~d}$ after injury will enable investigation of whether early proliferative responses result in the derivation of new, healthy oligodendrocytes and compact myelin. Protecting against early oxidative damage due to secondary degeneration will be worth considering in the design of therapeutic strategies aiming to preserve structure and function following neurotrauma.

\section{References}

Angelo M, Bendall SC, Finck R, Hale MB, Hitzman C, Borowsky AD, Levenson RM, Lowe JB, Liu SD, Zhao S, Natkunam Y, Nolan GP (2014) Multiplexed ion beam imaging of human breast tumors. Nat Med 20: 436-442. CrossRef Medline

Back SA, Gan X, Li Y, Rosenberg PA, Volpe JJ (1998) Maturationdependent vulnerability of oligodendrocytes to oxidative stress-induced death caused by glutathione depletion. J Neurosci 18:6241-6253. CrossRef Medline

Back SA, Han BH, Luo NL, Chricton CA, Xanthoudakis S, Tam J, Arvin KL, Holtzman DM (2002) Selective vulnerability of late oligodendrocyte progenitors to hypoxia-ischemia. J Neurosci 22:455-463. CrossRef Medline

Back SA, Luo NL, Mallinson RA, O’Malley JP, Wallen LD, Frei B, Morrow JD, Petito CK, Roberts CT Jr, Murdoch GH, Montine TJ (2005) Selective vulnerability of preterm white matter to oxidative damage defined by F2-isoprostanes. Ann Neurol 58:108-120. CrossRef Medline

Bandura DR, Baranov VI, Ornatsky OI, Antonov A, Kinach R, Lou X, Pavlov S, Vorobiev S, Dick JE, Tanner SD (2009) Mass cytometry: technique for real time single cell multitarget immunoassay based on inductively coupled plasma time-of-flight mass spectrometry. Anal Chem 81:6813-6822. CrossRef Medline

Bujalka H, Koenning M, Jackson S, Perreau VM, Pope B, Hay CM, Mitew S, Hill AF, Lu QR, Wegner M, Srinivasan R, Svaren J, Willingham M, Barres BA, Emery B (2013) MYRF is a membrane-associated transcription factor that autoproteolytically cleaves to directly activate myelin genes. PLoS Biol 11:e1001625. CrossRef Medline

Busch SA, Silver J (2007) The role of extracellular matrix in CNS regeneration. Curr Opin Neurobiol 17:120-127. CrossRef Medline

Butts BD, Houde C, Mehmet H (2008) Maturation-dependent sensitivity of oligodendrocyte lineage cells to apoptosis: implications for normal development and disease. Cell Death Differ 15:1178-1186. CrossRef Medline

Chen Q, Fischer A, Reagan JD, Yan LJ, Ames BN (1995) Oxidative DNA damage and senescence of human diploid fibroblast cells. Proc Natl Acad Sci U S A 92:4337-4341. CrossRef Medline

Covacci V, Torsello A, Palozza P, Sgambato A, Romano G, Boninsegna A, Cittadini A, Wolf FI (2001) DNA oxidative damage during differentiation of HL-60 human promyelocytic leukemia cells. Chem Res Toxicol 14:1492-1497. CrossRef Medline 
Coyle JT, Puttfarcken P (1993) Oxidative stress, glutamate, and neurodegenerative disorders. Science 262:689-695. CrossRef Medline

Degterev A, Yuan J (2008) Expansion and evolution of cell death programmes. Nat Rev Mol Cell Biol 9:378-390. CrossRef Medline

Emery B, Agalliu D, Cahoy JD, Watkins TA, Dugas JC, Mulinyawe SB, Ibrahim A, Ligon KL, Rowitch DH, Barres BA (2009) Myelin gene regulatory factor is a critical transcriptional regulator required for CNS myelination. Cell 138:172-185. CrossRef Medline

Eminli S, Utikal J, Arnold K, Jaenisch R, Hochedlinger K (2008) Reprogramming of neural progenitor cells into induced pluripotent stem cells in the absence of exogenous Sox2 expression. Stem Cells 26:2467-2474. CrossRef Medline

Fancy SP, Zhao C, Franklin RJ (2004) Increased expression of Nkx2. 2 and Olig2 identifies reactive oligodendrocyte progenitor cells responding to demyelination in the adult CNS. Mol Cell Neurosci 27:247-254. CrossRef Medline

Fancy SP, Kotter MR, Harrington EP, Huang JK, Zhao C, Rowitch DH, Franklin RJ (2010) Overcoming remyelination failure in multiple sclerosis and other myelin disorders. Exp Neurol 225:18-23. CrossRef Medline

Fern R, Möller T (2000) Rapid ischemic cell death in immature oligodendrocytes: a fatal glutamate release feedback loop. J Neurosci 20:34-42. CrossRef Medline

Fields RD (2015) A new mechanism of nervous system plasticity: activitydependent myelination. Nat Rev Neurosci 16:756-767. CrossRef Medline

Fitzgerald M, Bartlett CA, Evill L, Rodger J, Harvey AR, Dunlop SA (2009a) Secondary degeneration of the optic nerve following partial transection: the benefits of lomerizine. Exp Neurol 216:219-230. CrossRef Medline

Fitzgerald M, Payne SC, Bartlett CA, Evill L, Harvey AR, Dunlop SA (2009b) Secondary retinal ganglion cell death and the neuroprotective effects of the calcium channel blocker lomerizine. Invest Ophthalmol Vis Sci 50: 5456-5462. CrossRef Medline

Fitzgerald M, Bartlett CA, Harvey AR, Dunlop SA (2010) Early events of secondary degeneration after partial optic nerve transection: an immunohistochemical study. J Neurotrauma 27:439-452. CrossRef Medline

French HM, Reid M, Mamontov P, Simmons RA, Grinspan JB (2009) Oxidative stress disrupts oligodendrocyte maturation. J Neurosci Res 87: 3076-3087. CrossRef Medline

Fünfschilling U, Supplie LM, Mahad D, Boretius S, Saab AS, Edgar J, Brinkmann BG, Kassmann CM, Tzvetanova ID, Möbius W, Diaz F, Meijer D, Suter U, Hamprecht B, Sereda MW, Moraes CT, Frahm J, Goebbels S, Nave KA (2012) Glycolytic oligodendrocytes maintain myelin and longterm axonal integrity. Nature 485:517-521. CrossRef Medline

Garbern JY (2007) Pelizaeus-Merzbacher Disease: genetic and cellular pathogenesis. Cell Mol Life Sci 64:50-65. CrossRef Medline

Gautier HO, Evans KA, Volbracht K, James R, Sitnikov S, Lundgaard I, James F, Lao-Peregrin C, Reynolds R, Franklin RJ, Káradóttir RT (2015) Neuronal activity regulates remyelination via glutamate signalling to oligodendrocyte progenitors. Nat Commun 6:8518. CrossRef Medline

Guptarak J, Wiktorowicz JE, Sadygov RG, Zivadinovic D, PaulucciHolthauzen AA, Vergara L, Nesic O (2014) The cancer drug tamoxifen: a potential therapeutic treatment for spinal cord injury. J Neurotrauma 31:268-283. CrossRef Medline

Haider L, Fischer MT, Frischer JM, Bauer J, Höftberger R, Botond G, Esterbauer H, Binder CJ, Witztum JL, Lassmann H (2011) Oxidative damage in multiple sclerosis lesions. Brain 134:1914-1924. CrossRef Medline

Hartman TK, Wengenack TM, Poduslo JF, van Deursen JM (2007) Mutant mice with small amounts of BubR1 display accelerated age-related gliosis. Neurobiol Aging 28:921-927. CrossRef Medline

Havrda MC, Paolella BR, Ran C, Jering KS, Wray CM, Sullivan JM, Nailor A, Hitoshi Y, Israel MA (2014) Id2 mediates oligodendrocyte precursor cell maturation arrest and is tumorigenic in a PDGF-rich microenvironment. Cancer Res 74:1822-1832. CrossRef Medline

Herndon RM, Price DL, Weiner LP (1977) Regeneration of oligodendroglia during recovery from demyelinating disease. Science 195:693-694. CrossRef Medline

Hornig J, Fröb F, Vogl MR, Hermans-Borgmeyer I, Tamm ER, Wegner M (2013) The transcription factors Sox 10 and Myrf define an essential regulatory network module in differentiating oligodendrocytes. PLoS Genet 9:e1003907. CrossRef Medline

Juurlink BH, Thorburne SK, Hertz L (1998) Peroxide-scavenging deficit underlies oligodendrocyte susceptibility to oxidative stress. Glia 22:371378. CrossRef Medline

Koenning M, Jackson S, Hay CM, Faux C, Kilpatrick TJ, Willingham M, Emery B (2012) Myelin gene regulatory factor is required for maintenance of myelin and mature oligodendrocyte identity in the adult CNS. J Neurosci 32:12528-12542. CrossRef Medline

Liu Z, Hu X, Cai J, Liu B, Peng X, Wegner M, Qiu M (2007) Induction of oligodendrocyte differentiation by Olig2 and Sox10: evidence for reciprocal interactions and dosage-dependent mechanisms. Dev Biol 302:683693. CrossRef Medline

Lozić I, Hartz RV, Bartlett CA, Shaw JA, Archer M, Naidu PS, Smith NM, Dunlop SA, Iyer KS, Kilburn MR, Fitzgerald M (2016) Enabling dual cellular destinations of polymeric nanoparticles for treatment following partial injury to the central nervous system. Biomaterials 74:200-216. CrossRef Medline

Lu J, Ashwell KW, Waite P (2000) Advances in secondary spinal cord injury: role of apoptosis. Spine 25:1859-1866. CrossRef Medline

Ludwin SK (1979) An autoradiographic study of cellular proliferation in remyelination of the central nervous system. Am J Pathol 95:683-696. Medline

Mi S, Miller RH, Tang W, Lee X, Hu B, Wu W, Zhang Y, Shields CB, Zhang Y, Miklasz S, Shea D, Mason J, Franklin RJ, Ji B, Shao Z, Chédotal A, Bernard F, Roulois A, Xu J, Jung V, et al. (2009) Promotion of central nervous system remyelination by induced differentiation of oligodendrocyte precursor cells. Ann Neurol 65:304-315. CrossRef Medline

Mori S, Leblond CP (1970) Electron microscopic identification of three classes of oligodendrocytes and a preliminary study of their proliferative activity in the corpus callosum of young rats. J Comp Neurol 139:1-28. CrossRef Medline

Murphy MP (2009) How mitochondria produce reactive oxygen species. Biochem J 417:1-13. CrossRef Medline

Nomoto K, Tsuneyama K, Takahashi H, Murai Y, Takano Y (2008) Cytoplasmic fine granular expression of 8-hydroxydeoxyguanosine reflects early mitochondrial oxidative DNA damage in nonalcoholic fatty liver disease. Appl Immunohistochem Mol Morphol 16:71-75. CrossRef Medline

O’Hare Doig RL, Bartlett CA, Maghzal GJ, Lam M, Archer M, Stocker R, Fitzgerald M (2014) Reactive species and oxidative stress in optic nerve vulnerable to secondary degeneration. Exp Neurol 261:136-146. CrossRef Medline

Ozerdem U, Monosov E, Stallcup WB (2002) NG2 proteoglycan expression by pericytes in pathological microvasculature. Microvasc Res 63:129134. CrossRef Medline

Park E, Velumian AA, Fehlings MG (2004) The role of excitotoxicity in secondary mechanisms of spinal cord injury: a review with an emphasis on the implications for white matter degeneration. J Neurotrauma 21: 754-774. CrossRef Medline

Patel MN (2002) Oxidative stress, mitochondrial dysfunction, and epilepsy. Free Radic Res 36:1139-1146. CrossRef Medline

Payne SC, Bartlett CA, Harvey AR, Dunlop SA, Fitzgerald M (2012) Myelin sheath decompaction, axon swelling, and functional loss during chronic secondary degeneration in rat optic nerve. Invest Ophthalmol Vis Sci 53:6093-6101. CrossRef Medline

Payne SC, Bartlett CA, Savigni DL, Harvey AR, Dunlop SA, Fitzgerald M (2013) Early proliferation does not prevent the loss of oligodendrocyte progenitor cells during the chronic phase of secondary degeneration in a CNS white matter tract. PLoS One 8:e65710. CrossRef Medline

Richardson WD, Young KM, Tripathi RB, McKenzie I (2011) NG2-glia as multipotent neural stem cells: fact or fantasy? Neuron 70:661-673. CrossRef Medline

Richter C, Park JW, Ames BN (1988) Normal oxidative damage to mitochondrial and nuclear DNA is extensive. Proc Natl Acad Sci U S A 85: 6465-6467. CrossRef Medline

Rinholm JE, Vervaeke K, Tadross MR, Tkachuk AN, Kopek BG, Brown TA, Bergersen LH, Clayton DA (2016) Movement and structure of mitochondria in oligodendrocytes and their myelin sheaths. Glia 64:810-825. CrossRef Medline

Roth AD, Núñez MT (2016) Oligodendrocytes: functioning in a delicate balance between high metabolic requirements and oxidative damage. In: Glial cells in health and disease of the CNS, pp 167-181. New York, NY: Springer.

Stolt CC, Rehberg S, Ader M, Lommes P, Riethmacher D, Schachner M, 
Bartsch U, Wegner M (2002) Terminal differentiation of myelinforming oligodendrocytes depends on the transcription factor Sox10. Genes Dev 16:165-170. CrossRef Medline

Szymanski CR, Chiha W, Morellini N, Cummins N, Bartlett CA, O'Hare Doig RL, Savigni DL, Payne SC, Harvey AR, Dunlop SA, Fitzgerald M (2013) Paranode abnormalities and oxidative stress in optic nerve vulnerable to secondary degeneration: modulation by $670 \mathrm{~nm}$ light treatment. PLoS One 8:e66448. CrossRef Medline

Thorburne SK, Juurlink BH (1996) Low glutathione and high iron govern the susceptibility of oligodendroglial precursors to oxidative stress. J Neurochem 67:1014-1022. CrossRef Medline

Tsai JP, Liou JH, Yeh KT, Tai HC, Cheng YW, Chang HR (2011) Intensity of cytosol expression of 8-OHdG in normal renal tubules is associated with the severity of renal fibrosis. Swiss Med Wkly 141:w13268. CrossRef Medline

Volpe JJ (2011) Systemic inflammation, oligodendroglial maturation, and the encephalopathy of prematurity. Ann Neurol 70:525-529. CrossRef Medline

von Zglinicki T (2002) Oxidative stress shortens telomeres. Trends Biochem Sci 27:339-344. CrossRef Medline

Walsh DM, Röth PT, Holmes WR, Landman KA, Merson TD, Hughes BD (2016) Is cell migration or proliferation dominant in the formation of linear arrays of oligodendrocytes? J Theor Biol 406:17-30. CrossRef Medline

Wang S, Sdrulla A, Johnson JE, Yokota Y, Barres BA (2001) A role for the helix-loop-helix protein Id2 in the control of oligodendrocyte development. Neuron 29:603-614. CrossRef Medline

Watanabe M, Toyama Y, Nishiyama A (2002) Differentiation of prolifer- ated NG2-positive glial progenitor cells in a remyelinating lesion. J Neurosci Res 69:826-836. CrossRef Medline

Wegner M (2001) Expression of transcription factors during oligodendroglial development. Microsc Res Tech 52:746-752. CrossRef Medline

Xing YL, Röth PT, Stratton JA, Chuang BH, Danne J, Ellis SL, Ng SW, Kilpatrick TJ, Merson TD (2014) Adult neural precursor cells from the subventricular zone contribute significantly to oligodendrocyte regeneration and remyelination. J Neurosci 34:14128-14146. CrossRef Medline

Xiong Y, Rabchevsky AG, Hall ED (2007) Role of peroxynitrite in secondary oxidative damage after spinal cord injury. J Neurochem 100:639-649. CrossRef Medline

Ye X, Abou-Rayyah Y, Bischoff J, Ritchie A, Sebire NJ, Watts P, Churchill AJ, Bates DO (2016) Altered ratios of pro-and anti-angiogenic VEGF-A variants and pericyte expression of DLL4 disrupt vascular maturation in infantile haemangioma. J Pathol 239:139-151. CrossRef Medline

Young KM, Psachoulia K, Tripathi RB, Dunn SJ, Cossell L, Attwell D, Tohyama K, Richardson WD (2013) Oligodendrocyte dynamics in the healthy adult CNS: evidence for myelin remodeling. Neuron 77:873-885. CrossRef Medline

Zai LJ, Wrathall JR (2005) Cell proliferation and replacement following contusive spinal cord injury. Glia 50:247-257. CrossRef Medline

Zhu X, Hill RA, Nishiyama A (2008) NG2 cells generate oligodendrocytes and gray matter astrocytes in the spinal cord. Neuron Glia Biol 4:19-26. CrossRef Medline

Ziabreva I, Campbell G, Rist J, Zambonin J, Rorbach J, Wydro MM, Lassmann H, Franklin RJ, Mahad D (2010) Injury and differentiation following inhibition of mitochondrial respiratory chain complex IV in rat oligodendrocytes. Glia 58:1827-1837. CrossRef Medline 